University of Wollongong

Research Online

Australian Institute for Innovative Materials -

Papers

Australian Institute for Innovative Materials

$1-1-2018$

\title{
Structural design of anode materials for sodium-ion batteries
}

Wanlin Wang

University of Wollongong, Xijing University,ww268@uowmail.edu.au

Weijie Li

University of Wollongong,wl347@uowmail.edu.au

Shun Wang

Wenzhou University

Zongcheng Miao

University of Wollongong, Xijing University, zmiao@uow.edu.au

Hua-Kun Liu

University of Wollongong, hua@uow.edu.au

See next page for additional authors

Follow this and additional works at: https://ro.uow.edu.au/aiimpapers

Part of the Engineering Commons, and the Physical Sciences and Mathematics Commons

Research Online is the open access institutional repository for the University of Wollongong. For further information contact the UOW Library: research-pubs@uow.edu.au 


\title{
Structural design of anode materials for sodium-ion batteries
}

\author{
Abstract \\ With the high consumption and increasing price of lithium resources, sodium ion batteries (SIBs) have \\ been considered as attractive and promising potential alternatives to lithium ion batteries, owing to the \\ abundance and low cost of sodium resources, and the similar electrochemical properties of sodium to \\ lithium. Nevertheless, the lower energy density and limited cycling life of SIBs are still the main challenges \\ impeding their wide application. Tremendous work has been done on anode materials for SIBs, and \\ rational structural design is considered as an effective way to enhance their electrochemical \\ performance. In this review, different types of anode materials for SIBs are summarized according to their \\ reaction mechanism, and the problems for each type are pointed out. Specific structural design \\ approaches for each type of anode material to improve its sodium storage performance are described in \\ detail, and the benefits of different structural designs are explained as well.

\section{Disciplines} \\ Engineering | Physical Sciences and Mathematics

\section{Publication Details} \\ Wang, W., Li, W., Wang, S., Miao, Z., Liu, H. Hun. \& Chou, S. (2018). Structural design of anode materials for \\ sodium-ion batteries. Journal of Materials Chemistry A, 6 (15), 6183-6205.

\section{Authors} \\ Wanlin Wang, Weijie Li, Shun Wang, Zongcheng Miao, Hua-Kun Liu, and Shulei Chou
}




\section{Structural Design of Anode Materials for Sodium-Ion Batteries}

Wanlin Wang ${ }^{\mathrm{ab}}$, Weijie Li ${ }^{\mathrm{a}}$, Zongcheng Miao ${ }^{\mathrm{ab} *}$, Hua Kun Liu ${ }^{\mathrm{b}}$, and Shulei Chou ${ }^{\mathrm{b} *}$

${ }^{\text {a} K e y ~ L a b o r a t o r y ~ o f ~ O r g a n i c ~ P o l y m e r ~ P h o t o e l e c t r i c ~ M a t e r i a l s, ~ S c h o o l ~ o f ~ S c i e n c e, ~ X i j i n g ~}$ University, Xi'an, 710123, Shaanxi, People's Republic of China

*E-mail: miaozongcheng@ xijing.edu.cn

${ }^{\mathrm{b}}$ Institute for Superconducting and Electronic Materials, Australian Institute for Innovative Materials, University of Wollongong, Innovation Campus, North Wollongong, NSW 2500 Australia

*corresponding author email: shulei@uow.edu.au

With the high consumption and increasing price of lithium resources, sodium ion batteries (SIBs) have been considered as attractive and promising potential alternatives to lithium ion batteries, owing to the abundance and low cost of sodium resources, and the similar electrochemical properties of sodium to lithium. Nevertheless, the lower energy density and limited cycling life of SIBs are still the main challenges impeding their wide application. Tremendous work has been done on anode materials for SIBs, and rational structural design is considered as an effective way to enhance their electrochemical performance. In this review, different types of anode materials for SIBs are summarized according to their reaction mechanism, and the problems for each type are pointed out. Specific structural design approaches for each type of anode material to improve its sodium storage performance are described in detail, and the benefits of different structural design are explained as well.

\section{Introduction}

During the past decade, the global warming effect has always been a hot topic due to our extensive use of fossil fuels, which provide the main power supply for human consumption. It is extremely important to find alternative energy storage technologies for power generation, such as utilization of solar, wind, and tidal energy ${ }^{1}$. All of these types of clean energy cannot be used directly, however, because they are not stable and continuous. In order to overcome, batteries are considered as wonderful devices that could meet the demand for electrochemical energy storage owing to their high energy and power density, which are superior overall compared to other energy storage systems such as supercapacitors and fuel cells ${ }^{2}$. Since the 
commercialization of lithium-ion batteries (LIBs) in 1990, they have captured the market for portable electronic devices, hybrid electric vehicles, large-scale industrial equipment, etc. ${ }^{3}$. Nevertheless, considering the limited nature of lithium resources in the Earth's crust, it is quite likely that the world might run out of it in the foreseeable future ${ }^{4}$. Meanwhile, with the price of lithium increasing year by year, finding other cheap types of alternative electrochemical batteries is urgently needed, and sodium-ion batteries (SIBs) are part of this trend ${ }^{5}$.

Sodium-ion battery technology is a promising system as a substitute for LIBs for lowcost applications due to the lower price, natural abundance, and similar intercalation chemistry of sodium to lithium ${ }^{6}$. So far, tremendous efforts have been made to explore suitable Na-host materials with high reversible capacity, rapid Na-ion insertion/extraction, and long cycling stability ${ }^{7}$. Nevertheless, the electrochemical performance of SIBs is still unsatisfactory because the radius of the Na-ion (1.02 $\AA$ ) is much larger than that of the Li-ion $(0.76 \AA)$, which causes structural and phase instability, sluggish transport properties, and interphase formation ${ }^{8}$. In addition, sodium $\left(23 \mathrm{~g} \mathrm{~mol}^{-1}\right)$ is also heavier than lithium $(6.9 \mathrm{~g}$ $\mathrm{mol}^{-1}$ ) and has a higher standard electrode potential (-2.71 V vs. standard hydrogen electrode (SHE) as compared to $-3.02 \mathrm{~V}$ vs. SHE for lithium), which reveals another disadvantage of SIBs in terms of low energy density. Therefore, it is imperative to seek appropriate electrode materials and create new synthesis methods for SIBs to enhance their electrochemical performance.

Various kinds of cathode materials have been researched, including layered and tunnel type transition metal oxides, transition metal sulphides and fluorides, oxyanionic compounds, Prussian blue analogues, and polymers ${ }^{9,10}$. Most of them were tested in coin cells using metallic sodium as the counterpart anode, and the formation of dendrites has always been a safety issue that has inspired researchers to look for new types of anode materials ${ }^{11,12}$. The anode materials for SIBs can be categorised into three groups, based on the reaction mechanism during sodiation/desodiation processes ${ }^{13}$ :(1) the insertion reaction materials, which include carbonaceous materials and titanium-based oxides; (2) the conversion reaction materials, represented by transition metal oxides or transition metal sulphides; and (3) the alloying reaction materials, including Na-metal alloying compounds containing elements from groups 14 or 15 . There are some characteristic drawbacks for each type, however, such as low specific capacity and poor rate capability for the insertion type ${ }^{14}$, while the conversion and alloying reaction materials often suffer from huge volume expansion during 
charge/discharge processes due to the continuous self-pulverization of the electrode materials 15. Therefore, the search for anode materials with superior electrochemical performance is still an obstacle and challenge for the development of SIBs. There are some summaries of the different types of anode materials for SIBs ${ }^{16,17}$, and even some reports on specific types of anode materials, such as review of carbon materials ${ }^{18}$, alloy based materials ${ }^{19}$ and phosphorus and phosphide materials ${ }^{20}$, but there is no report so far on anode materials for SIBs from the structural design perspective. The rational design of structures for anode materials plays an important role in enhancing their electrochemical properties. We regard nano-sized materials as a big group, which includes nano particles, nano cubes, nano fibers or nano sheets, these different structures could also make up 3D network morphology. The advantage of nanostructured materials is that they have uniform structures with short diffusion path for both Na-ions and electrons. Moreover, as loads of anode materials for SIBs showed the sluggish diffusion kinetic, suffer from huge volume expansion, other types of complex structures that contain holes inside are also important for improving the electrochemical performance because they could provide large contact area for electrolyte and holes inside of materials could also be considered as buffer zone for accommodating large volume change and facilitate the transfer of electrons and ions as well, such as porous and hollow structure. Some other hierarchical structures are also useful such as core-shell or yolk-shell structure, which contain shell that could suppress particle aggregation and volume change effectively, the space in yolk-shell structure could be considered as wonderful buffer zone as well, however, these two kinds of structures are more complicated in synthesis process. Therefore, we categorised anode materials for SIBs into these three groups: (1) nanostructures; (2) porous or hollow structures; and (3) core-shell or yolk-shell structures. The schematic figures of different structures are illustrated in Fig. 1. Sometimes, there are combinations of these special structures when fabricating anode materials for SIBs in order to achieve better electrochemical performance. In this review, we have summarized different types of anode materials for SIBs in sequence of their reaction mechanism and illustrate the structural design for each type in sequence of three types of structures above, respectively. 

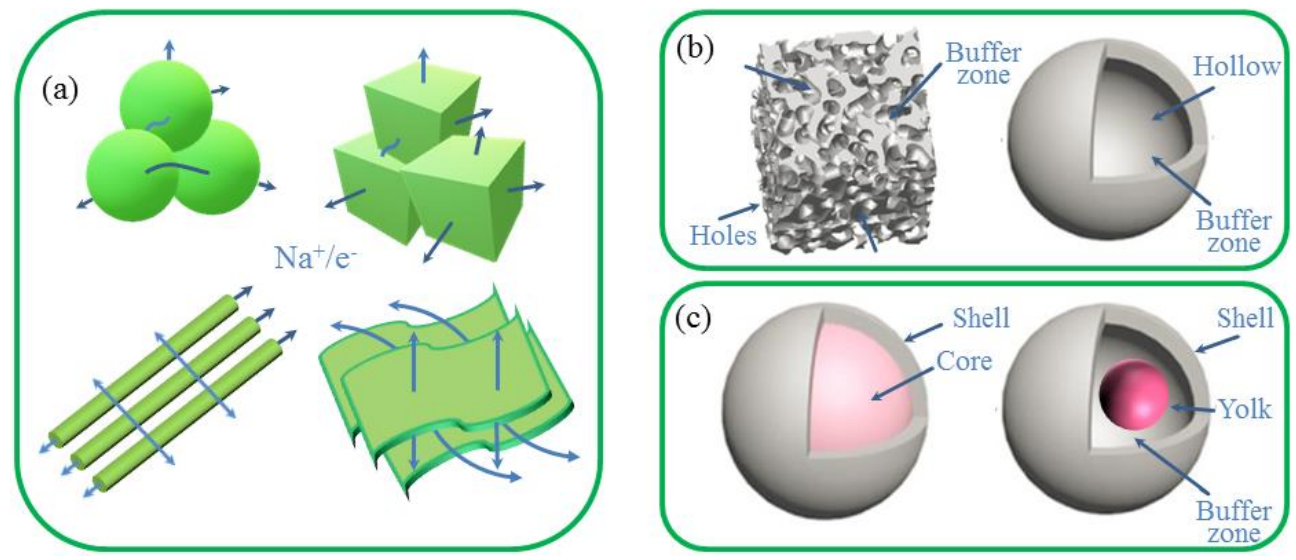

Figure 1. Schematic figures of (a) Nanostructures (spheres, cubes, fibers and sheets), (b) porous and hollow structures, (c) core-shell and yolk-shell structures.

\section{Anode materials for SIBs and structural design}

\subsection{Insertion materials and structural design}

There are mainly two kinds of anode materials based on insertion reaction including carbonbased materials and titanium-based materials for SIBs. Both of them have been widely investigated due to their structure that favourable for intercalation of $\mathrm{Na}^{+}$ions. Other advantages like low cost and low operational potential for each also made them promising materials as ideal anode for SIBs. However, the drawbacks such as poor reversibility, rate capability and low capacity should not be neglected. Different structural designs have been adopted, which could enhance their electrochemical performance and described as below.

\subsubsection{Carbonaceous materials}

Carbon-based materials have been investigated as electrode materials for energy storage and conversion devices because they have several important advantages, such as abundant resources, renewability, cost effectiveness, and moderate conductivity. Graphite is the most common anode material for commercial LIBs, but it is not suitable for SIBs because the large $\mathrm{Na}^{+}$ion cannot be intercalated into graphite and because of the absence of stable $\mathrm{Na}-\mathrm{C}$ binary compounds. In 2000, a hard carbon was first found by Dahn and co-workers that exhibited a high reversible capacity of about $300 \mathrm{~mA} \mathrm{~h} \mathrm{~g}^{-121}$, owing to its special disordered structure. Later on, much further work was done on hard carbon materials, but their low first cycle coulombic efficiency and poor reversibility are still problems for them ${ }^{22-24}$.

During recent years, the investigation of carbonaceous materials for SIBs has been basically on hard carbon materials, heteroatom-doped carbon materials, and biomass derived 
carbon materials. Many of them were designed in nanostructured forms, including carbon nanofibers, nanosheets, nanospheres, etc ${ }^{25-27}$. Nanostructured carbon-based anode materials have provided new opportunities to improve the properties of SIBs because of their structural stability and good connectivity for electrical conduction. Cao et al. reported hollow carbon nanowires obtained by direct pyrolyzation of a hollow polyaniline nanowire precursor. This novel carbon nanostructure displayed a high reversible capacity $\left(251 \mathrm{~mA} \mathrm{~h} \mathrm{~g}^{-1}\right.$ at $\left.50 \mathrm{~mA} \mathrm{~g}^{-1}\right)$ and excellent cycling stability over 400 cycles. A reversible capacity of over $200 \mathrm{~mA} \mathrm{~h} \mathrm{~g}$ and more than $90 \%$ capacity retention was obtained at $125 \mathrm{~mA} \mathrm{~g}^{-1}$ after 200 cycles. Even at the current density of $500 \mathrm{~mA} \mathrm{~g}^{-1}$ (2 C), a high reversible capacity of $149 \mathrm{~mA} \mathrm{~h} \mathrm{~g}^{-1}$ could be observed. The good $\mathrm{Na}^{+}$insertion properties can be attributed to the short diffusion distance because of the nanosized structure ${ }^{28}$. In addition, some advanced synthesis methods also can be utilized in designing carbon nanofiber materials. Chen and his co-workers fabricated carbon nanofibers by adopting the electrospinning method followed by a thermal treatment ${ }^{29}$. The morphology and electrochemical performance of this nanofiber are shown in Fig. 2. It delivered an initial reversible capacity of $233 \mathrm{~mA} \mathrm{~h} \mathrm{~g}^{-1}$ at a current density of $50 \mathrm{~mA} \mathrm{~g}^{-1}$, and a capacity of $82 \mathrm{~mA} \mathrm{~h} \mathrm{~g}^{-1}$ was maintained even at the high current density of $2 \mathrm{~A} \mathrm{~g}^{-1}$. It also achieved an excellent capacity retention ratio of $97.7 \%$ over 200 cycles. The electrospinning technique is one of the most effective ways to synthesize one-dimensional nanostructured materials, which are generally considered to be high-capacity and electrochemically stable due to their uniform structure and good electrical connectivity. On the other hand, the electrospinning method is regarded as an economical way to design binder-free, currentcollector-free carbon nanofiber-based anode materials that could reduce the cost of the battery by simplifying the cell packing process and eliminating inactive weight. This special design method is also able to improve the mechanical flexibility, energy density, and cycling capability of the carbon nanofiber electrode at the same time ${ }^{30,31}$. In addition, many researchers also reported that better rate performances of carbon nanofiber materials could be achieved if the special structure is combined with heteroatom doping such as with $\mathrm{N}, \mathrm{P}$, and $\mathrm{S}$ ${ }^{32-34}$. For example, Fu et al. fabricated nitrogen doped porous carbon fibres as anode materials for SIBs, and they showed excellent electrochemical performance, especially in their rate capability. The specific capacity could remain at 100 and $75 \mathrm{~mA} \mathrm{~h} \mathrm{~g}^{-1}$, even at the high current density of 5 and $10 \mathrm{~A} \mathrm{~g}^{-1}$, respectively ${ }^{33}$. The superior performance can be attributed to their $\mathrm{N}$-doped sites and functionalized groups, which are capable of capturing sodium ions rapidly and reversibly through surface adsorption and surface redox reactions ${ }^{34}$. 

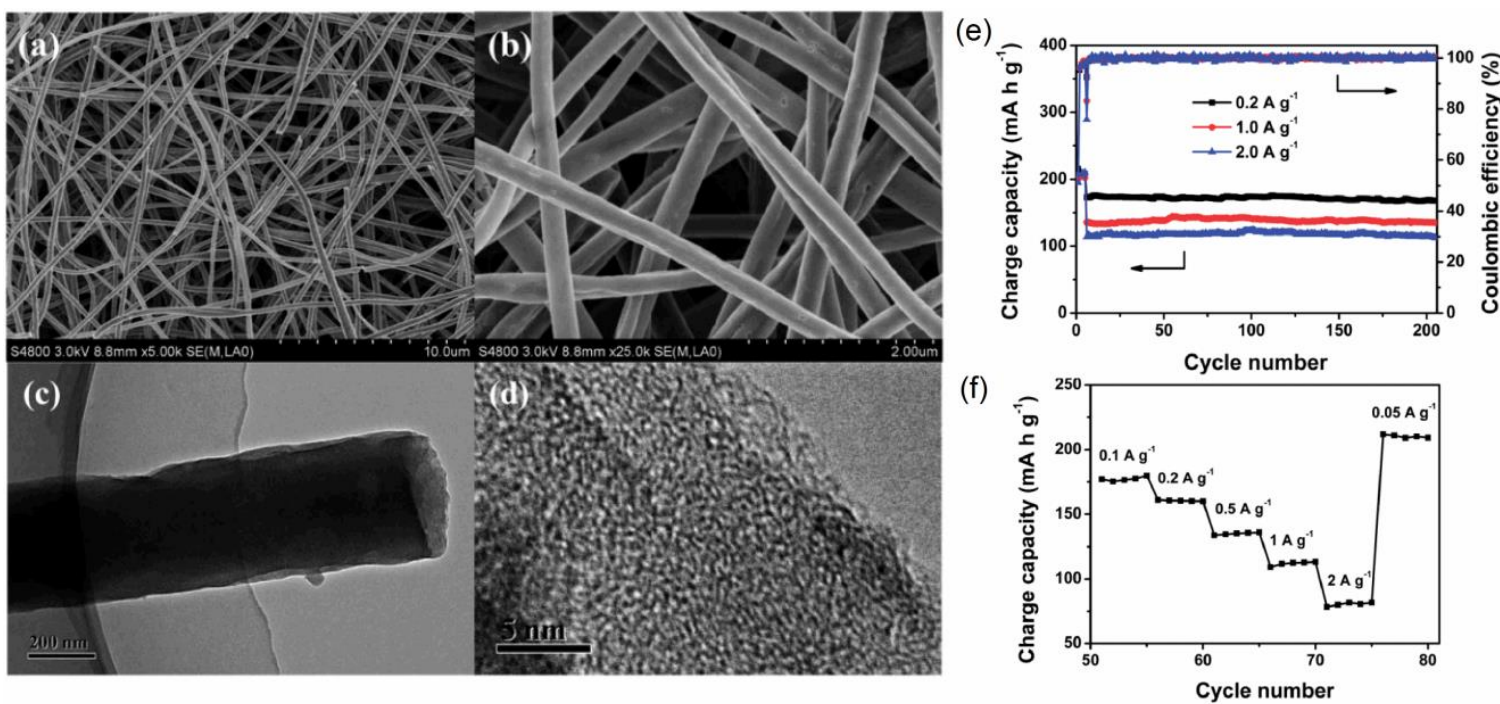

Figure 2. (a) Low-magnification and (b) high-magnification FESEM images of the carbon fibres (CFs), (c) lowmagnification and (d) high-magnification HRTEM images of the CFs; (e) cycling performance and (f) rate performance of the CFs. Reproduced with permission ${ }^{29}$. Copyright $@ 2014$, Royal Society of Chemistry.

Multidimensional carbon-based materials have also drawn attention since they show excellent electrochemical properties on account of their larger contact area with the electrolyte and because they are kinetically favourable for the transport of $\mathrm{Na}$-ions and electrons. For instance, a kind of carbon nanosheet framework materials was synthesized by Ding et al. They created this special structure by using peat moss as an ideal precursor due to its unique cellular cross-linked structure. The resultant material is composed of threedimensional (3D) microporous interconnected networks of carbon nanosheets (as thin as 60 $\mathrm{nm})$. The precursor was calcined at a range of temperatures from 600 to $1400{ }^{\circ} \mathrm{C}$, followed by activation under air atmosphere to optimize performance. Finally, the sample (with carbonization at $1100{ }^{\circ} \mathrm{C}$ ) demonstrated a stable cycling capacity of $298 \mathrm{~mA} \mathrm{~h} \mathrm{~g}^{-1}$ (after 10 cycles, $50 \mathrm{~mA} \mathrm{~g}^{-1}$ ), with $150 \mathrm{~mA} \mathrm{~h} \mathrm{~g}^{-1}$ of charge accumulated between 0.1 and $0.001 \mathrm{~V}$ with negligible voltage hysteresis in that region, nearly $100 \%$ coulombic efficiency during cycling, with superb cycling retention and high rate capacity $\left(255 \mathrm{~mA} \mathrm{~h} \mathrm{~g}^{-1}\right.$ at the $210^{\text {th }}$ cycle, and stable capacity of $203 \mathrm{~mA} \mathrm{~h} \mathrm{~g}^{-1}$ at $\left.500 \mathrm{~mA} \mathrm{~g}^{-1}\right)^{35}$. Designing 3D structures for electrode materials is always a good way to improve the performance due to the fast ion and electron transportation.

Combining the electrospinning technique with $\mathrm{N}$-doping makes it possible to optimize the electrochemical properties of carbon nanofiber films as well. For instance, Wang et al. used this strategy to fabricate a free-standing flexible $\mathrm{N}$-doped carbon nanofiber film with a 
three dimensional network structure. It exhibited a cycle life of 7000 cycles with capacity retention of $99 \%\left(210 \mathrm{~mA} \mathrm{~h} \mathrm{~g}^{-1}\right.$ at a current density of $\left.5 \mathrm{~A} \mathrm{~g} \mathrm{~g}^{-1}\right)$. The superior performance could be ascribed to its flexible and stable structure and the uniform distribution of micropores in the matrix ${ }^{36}$. This unique nanostructure could effectively facilitate the insertion/extraction of sodium ions. Some other novel 3D structured carbon anode materials also have been reported, including graphene foams ${ }^{37}$, 3D porous carbon frameworks derived from carbon quantum dots ${ }^{38}$, a 3D hard carbon matrix ${ }^{39}$, etc. They all displayed excellent electrochemical performance due to their special multidimensional structures.

Apart from the carbonaceous nanofiber and nanosheet materials mentioned above, another important type of morphology design is spherical carbon-based materials for SIBs, which have been widely investigated when it comes to consideration of electrode packing density and volumetric energy density. Compared to other types of materials, the spherical morphology is regarded as an ideal structure due to the homogeneous particle distribution. It is also able to avoid excessive build-up of the solid electrolyte interphase (SEI) and $\mathrm{Na}$ consumption at sharp edges and irregularities in the morphology. Vilas et al. reported spherical carbon as a new high-rate anode materials for SIBs ${ }^{40}$. The spherical carbon particles were synthesized by an autogenic approach and had an average diameter of $4 \mu \mathrm{m}$. This feature and the spherical morphology promote low reactivity with the electrolyte, which assists in the material's highly reversible (de)sodiation. Excellent rate capability was obtained with capacity of $40 \mathrm{~mA} \mathrm{~h} \mathrm{~g}$ at current density of $1.5 \mathrm{~A} \mathrm{~g}^{-1}$. Some modifications of carbon sphere materials can be utilized to further enhance their electrochemical properties as well, such as hollow structures, nanosized structures, and heteroatom doping. In 2012, hollow carbon nanospheres were reported by Tang and his co-workers for the first time ${ }^{41}$. The advantage of designing hollow structures is that they could boost mass transport by offering a large surface area and a short diffusion distance. A template method combined with hydrothermal carbonization of glucose was used in creating the unique hollow structure, resulting in a thin carbon shell with thickness of $12 \mathrm{~nm}$. The shell was also analysed by highresolution transmission electron microscopy (HRTEM), with the images showing that it is composed of 2-3 short carbon layers. It was proposed that the hollow nanosphere structure endows the materials with excellent sodium storage performance. TEM images, a schematic illustration, and the electrochemical performance of these hollow carbon nanospheres are shown in Fig. 3. As can be seen, a reversible capacity of $150 \mathrm{~mA} \mathrm{~h} \mathrm{~g}{ }^{-1}$ is obtained in the voltage range of $0-1.5 \mathrm{~V}$, and this material also demonstrates superior rate capability, with 
reversible capacities of $168,142,120,100$, and $75 \mathrm{~mA} \mathrm{~h} \mathrm{~g}^{-1}$ at current densities of $0.2,0.5,1$, 2 , and $5 \mathrm{~A} \mathrm{~g}^{-1}$, respectively. In addition, porous nitrogen doped carbon spheres were also reported by Li et al. They used the template-assisted method to design porous structures combined with $\mathrm{N}$-doping, and they found that the porous structure is a critical factor for improving the electrochemical performances of carbon anode materials. The electrochemical performance of the as-prepared material showed a superior rate capability of $155 \mathrm{~mA} \mathrm{~h} \mathrm{~g}^{-1}$ at $1 \mathrm{~A} \mathrm{~g}^{-1}$, and it also exhibited outstanding cycling stability with $206 \mathrm{~mA} \mathrm{~h} \mathrm{~g}{ }^{-1}$ after 600 cycles at $0.2 \mathrm{~A} \mathrm{~g}^{-1}{ }^{42}$. In addition to single heteroatom-doping, two different heteroatom-co-doping methods were also used to fabricate a hierarchical sulphur and nitrogen co-doped carbon microsphere material by $\mathrm{Xu}$ et al. ${ }^{43}$. They designed and fabricated the carbon microspheres by the pyrolyzing method combined with $\mathrm{N}$ and $\mathrm{S}$ dual-doping, leading to enhancement of the $\mathrm{Na}$ adsorption capability, mobility, and electronic conductivity. The results demonstrate a high-performance anode for SIBs, for example, a reversible capacity of $150 \mathrm{~mA} \mathrm{~h} \mathrm{~g}^{-1}$ can be observed after 3400 cycles, which is much better than for other single heteroatom-doped carbon anode materials for SIBs.
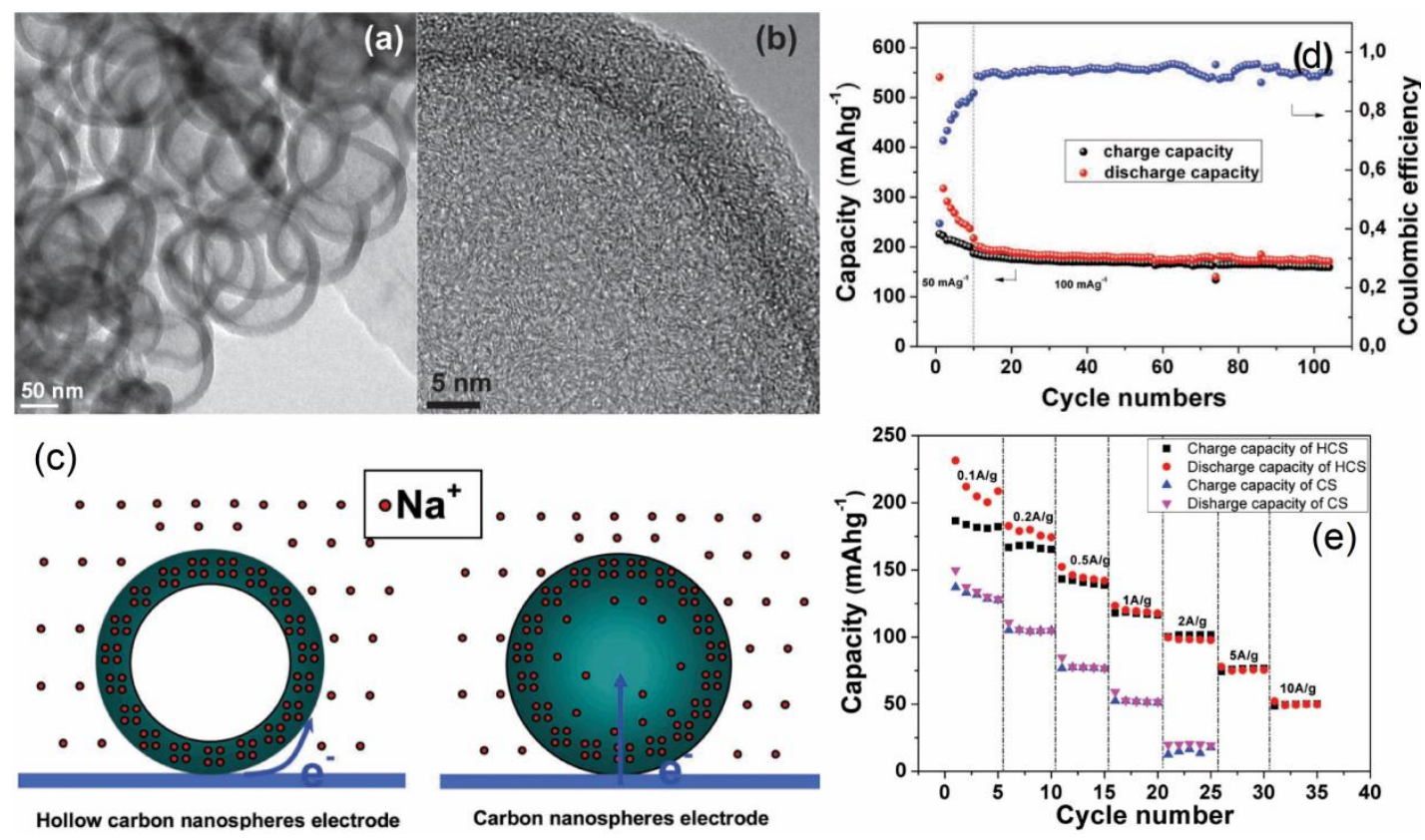

Figure 3. (a) TEM image and (b) HRTEM image of hollow carbon nanospheres; (c) Schematic illustration of the electrochemical reaction process for hollow carbon nanospheres and carbon spheres; (d) Cycling performance and (e) rate performance of hollow carbon nanospheres (HCS) and carbon spheres (CS) at different rates. Reproduced with permission ${ }^{41}$. Copyright @ 2012 WILEY-VCH Verlag Gmbh \& Co. KGaA, Weinheim.

Many single-type special structures for carbon-based anode materials for SIBs have been designed and reported so far. Nevertheless, combining different materials with special 
structures could yield carbon composites as anode materials for SIBs, which have complicated structural design and are expected to achieve better electrochemical performance. Yan et al. created a sandwich-like hierarchically porous carbon/graphene (G@HPC) composite by combining the advantages of both porous carbon and graphene. The porous carbon could enhance the sodium storage capacity by optimizing the transport pathways of the $\mathrm{Na}^{+}$ions, and graphene is one of the best two-dimensional (2D) carbon materials, with large surface area, chemical stability, and high electronic conductivity ${ }^{44}$. The morphology, a schematic illustration, and the electrochemical performance of this composite are displayed in Fig. 4. As can be seen, this hierarchical structured material exhibited a remarkable cycling stability over 1000 cycles with capacity of $250 \mathrm{~mA} \mathrm{~h} \mathrm{~g}^{-1}$ at $1 \mathrm{~A} \mathrm{~g}^{-1}$. Similarly, N-doped carbon/graphene hybrid anode material was prepared by Liu et al. through in-situ polymerization followed by pyrolysis. It showed a sandwich-like structure and displayed a rate capability of $94 \mathrm{~mA} \mathrm{~h} \mathrm{~g}^{-1}$ at $5 \mathrm{~A} \mathrm{~g}^{-1}$ and good cycling stability with capacity retention of $89 \%$ over 200 cycles at $50 \mathrm{~mA} \mathrm{~g}^{-1}$. Its excellent properties were attributed to its unique structure, in which the carbon nanosheets could shorten the ion diffusion distance and the sandwiched graphene guaranteed fast electron transportation ${ }^{45}$. Another complex carbon based composite was reported by $\mathrm{Qu}$ and co-workers ${ }^{46}$. They designed a core-shellstructured hollow carbon nanofiber@N-doped porous carbon composite material. Ultra-long cycling stability over 2500 cycles with capacity around $150 \mathrm{~mA} \mathrm{~h} \mathrm{~g}{ }^{-1}$ at $500 \mathrm{~mA} \mathrm{~g}^{-1}$ was obtained. The outstanding electrochemical performance may be attributable to the special core-shell and hollow structure that could improve the electrode structure and the capacity at the same time. Therefore, constructing anode carbon composites for SIBs involves novel structural design and shows a promising direction for development in the future. 

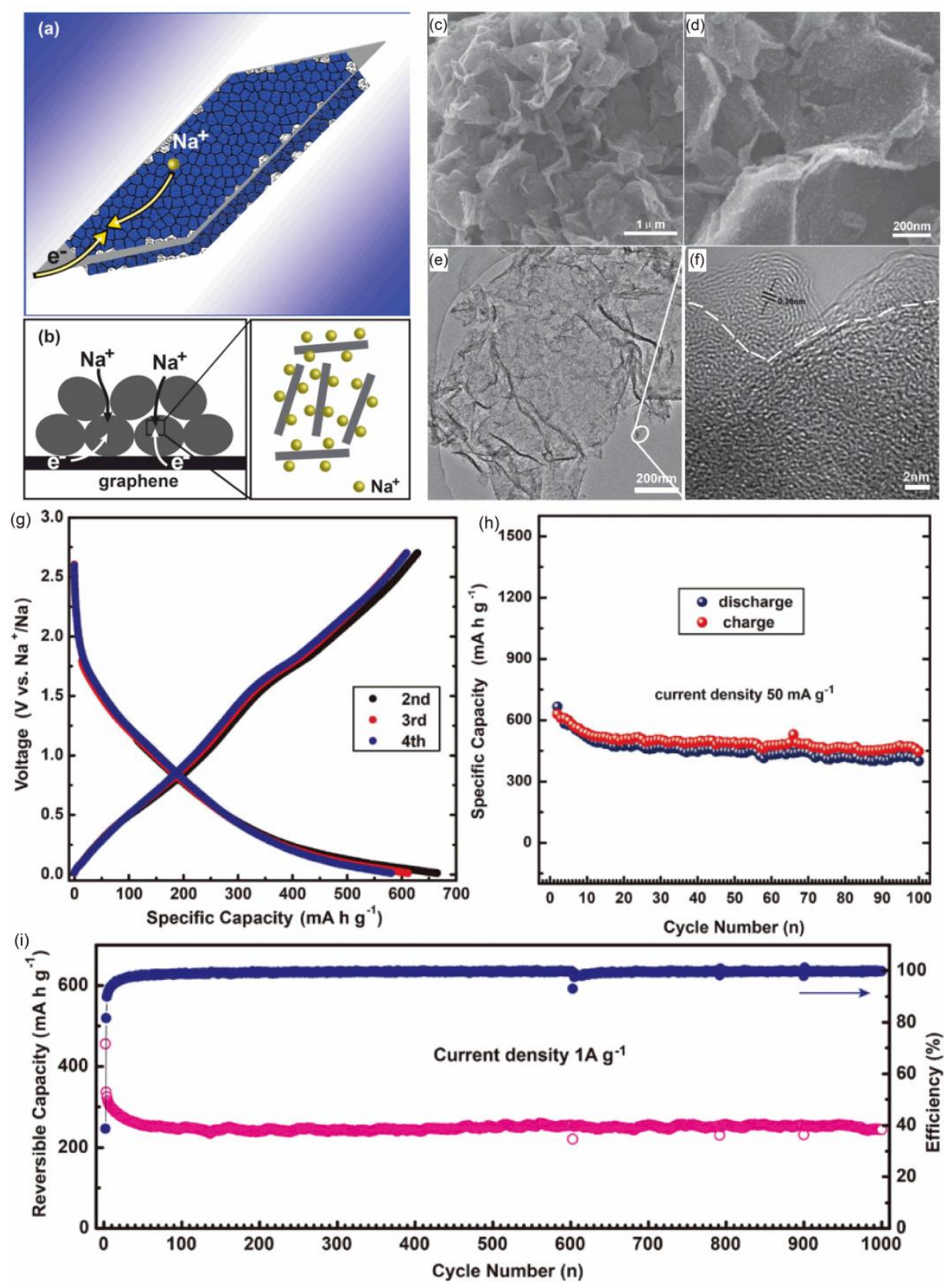

Figure 4. (a) Schematic illustration of the structure of G@HPC; (b) Schematic illustration of sodium storage in the G@HPC, (c, d) SEM images, (e) TEM image, and (f) HRTEM image of the G@HPC composite, (g) Charge-discharge curves at a current density of $0.05 \mathrm{~A} \mathrm{~g}^{-1}$; Cycling performances at (h) $0.05 \mathrm{~A} \mathrm{~g}^{-1}$ and (i) $1 \mathrm{~A}$ $\mathrm{g}^{-1}$. Reproduced with permission ${ }^{44}$. Copyright $(2) 2014$ WILEY-VCH Verlag Gmbh \& Co. KGaA, Weinheim.

\subsubsection{Titanium-based oxides}

There are still many concerns about the low operating potential for carbon-based materials, which may cause the safety problems when it comes to practical application. Titanium based oxides are regarded as another important type of insertion material for SIB anodes due to several advantages such as reasonable operation voltage, low cost, and environmental friendliness. Most of the studies on them have been focused on titanium dioxide, and some of 
the structural design work on $\mathrm{TiO}_{2}$ has been reported. In addition, lithium titanate and sodium titanate compounds were also investigated ${ }^{47}$, but most related works have focused on finding the sodiation/desodiation mechanism and improving the electrochemical performance of such materials. In this part, we mainly describe some of the structural design work on titanate dioxides and discuss a few examples on lithium titanate compounds.

Among the different types of titanate dioxides, anatase $\mathrm{TiO}_{2}$ is one of the best anode materials for SIBs because its activation barrier is close to that of lithium when large $\mathrm{Na}^{+}$ions are inserted into the anatase lattice. Anatase $\mathrm{TiO}_{2}$ also has a crystal structure featuring $3 \mathrm{D}$ networks, giving possible interstitial sites for $\mathrm{Na}^{+}$accommodation and suitable sized pathways for $\mathrm{Na}^{+}$diffusion ${ }^{48}$. Designing $\mathrm{TiO}_{2}$ materials in nanostructured form is also a good choice for fabricating $\mathrm{TiO}_{2}$ materials in order to improve their electrochemical performance. In 2013, anatase $\mathrm{TiO}_{2}$ nanocrystals were successfully employed as anodes for rechargeable Na-ion batteries for the first time ${ }^{49}$. A template method was used and followed by a hydrolysis treatment and annealing process. The particle size of the nanocrystalline $\mathrm{TiO}_{2}$ was about 10-15 nm, and it also showed a mesoporous structure. It exhibited a highly stable cycling performance, with capacity of $\sim 150 \mathrm{~mA} \mathrm{~h} \mathrm{~g}^{-1}$ over 100 cycles, and was able to retain this capacity after being cycled at the high current density of $2 \mathrm{~A} \mathrm{~g}^{-1}$. After the first study of anatase $\mathrm{TiO}_{2}$ nanocrystals as anode materials for SIBs, other researchers thought that the morphology of anatase $\mathrm{TiO}_{2}$ nanocrystals could be controlled in order to improve the charge transport properties. Its structural features could also be optimized to enhance its electrochemical properties and promote material interaction with the conductive network and the electrolyte ${ }^{50}$. Gianluca et al. synthesized three different nanostructured $\mathrm{TiO}_{2}$ morphologies, including rhombic elongated (RE), rhombic (R), and nanobar (NB)-like particles, and introduced graphene into the sample to improve the conductivity. The results showed that a $\mathrm{RE} \mathrm{TiO}_{2}$-based composite electrode was able to deliver outstanding stability over long cycling ( $150 \mathrm{~mA} \mathrm{~h} \mathrm{~g}^{-1}$ for more than 600 cycles in the $1.5-0.1 \mathrm{~V}$ potential range), something never previously achieved with such a low content of carbonaceous substrate $(5 \%)$.

There are also some other nanostructured anatase $\mathrm{TiO}_{2}$ materials that have been reported. For example, $\mathrm{TiO}_{2}$ nanofiber was designed by Yeo et al. using the electrospinning technique 51. The $\mathrm{TiO}_{2}$ nanofiber (NF) was then wrapped in graphene in order to enhance its electrical conductivity, which is a main drawback of $\mathrm{TiO}_{2}$. A schematic illustration of the synthesis of this material and its electrochemical performance are displayed in Fig. 5. As shown in the 
figure, the reduced graphene oxide $(\mathrm{rGO}) @ \mathrm{TiO}_{2} \mathrm{NFs}$ exhibited a significantly improved initial capacity of $217 \mathrm{~mA} \mathrm{~h} \mathrm{~g}^{-1}$ compared to the bare NFs, and $85 \%$ capacity retention was obtained after 200 cycles at $0.2 \mathrm{C}$. The average Coulombic efficiency was as high as $99.7 \%$ until the $200^{\text {th }}$ cycle, even at the $5 \mathrm{C}$ rate, except for the initial cycle. Xiong and co-workers also synthesized $\mathrm{TiO}_{2} / \mathrm{C}$ nanofibers by the electrospinning method, and they exhibited a high reversible capacity of $\sim 302.4 \mathrm{~mA} \mathrm{~h} \mathrm{~g}^{-1}$ and excellent rate performance, with capacity of 164.9 $\mathrm{mA} \mathrm{h} \mathrm{g} \mathrm{g}^{-1}$ at the high current density of $2000 \mathrm{~mA} \mathrm{~g}^{-1}$. These nanofibers displayed remarkable long-term cycling stability with almost no capacity loss over 1000 cycles. The extraordinary performance can be attributed to the special structure, in which $\mathrm{TiO}_{2}$ nanocrystals were embedded in the carbon matrix, which could prevent them from aggregating and protect them from attack by the electrolyte ${ }^{52}$. For comparison with $\mathrm{TiO}_{2}$ nanotubes and nanoparticles, Yang and his co-workers fabricated $\mathrm{TiO}_{2}$ nanocubes with superior electrochemical performance. They showed reversible capacities of $\sim 150$ and $\sim 100 \mathrm{~mA} \mathrm{~h} \mathrm{~g}^{-1}$ at $2 \mathrm{C}$ and $10 \mathrm{C}$ over 1000 cycles, with capacity retention of $94 \%$ and $94.6 \%$, respectively, and high rate performance could be observed as well (50 $\mathrm{mA} \mathrm{h} \mathrm{g}^{-1}$ at $\left.50 \mathrm{C}\right)$. The superior cycling stability can be attributed to the recoverability of the structure and morphology during sodiation/desodiation processes, which was confirmed by ex-situ scanning electron microscopy (SEM) and X-ray diffraction (XRD) analysis. After 1000 cycles, the cubic morphology of $\mathrm{TiO}_{2}$ particles was retained very well. The excellent rate performance came from the 100 exposed facets of $\mathrm{TiO}_{2}$ nanocubes, which is the direction for $\mathrm{Na}^{+}$transportation. Such surface structures endowed the nanocubes with higher reactivity, thus enabling them to undertake rapid uptake and release of sodium ions ${ }^{53}$. 
(a)

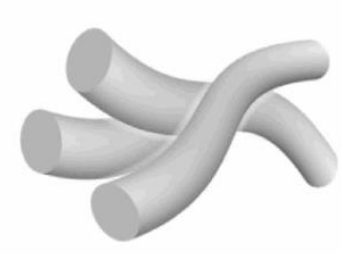

Electrospun NFs

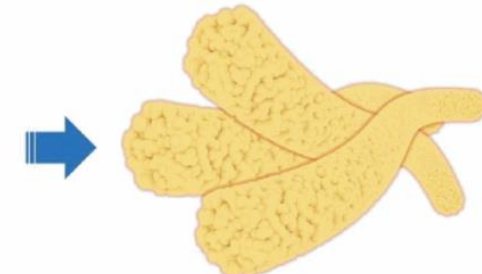

$\mathrm{TiO}_{2} \mathrm{NFs}$

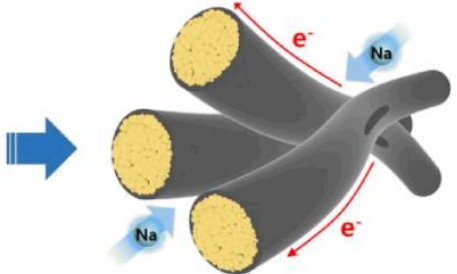

rGO@TiO ${ }_{2}$ NFs

(b)

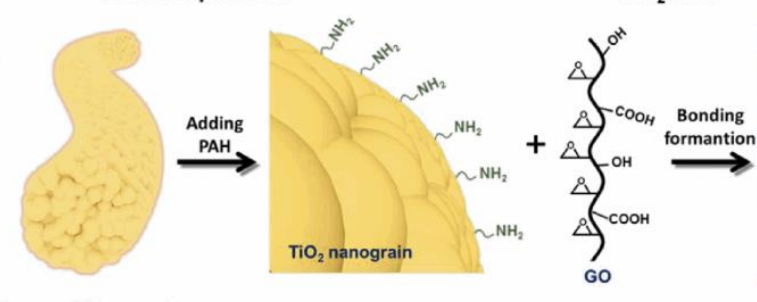

i) Anatase $\mathrm{TiO}_{2}$ nanofiber

ii) PAH-modified $\mathrm{TiO}_{2} \mathrm{NFs}+$ Graphene Oxide

(c) 250
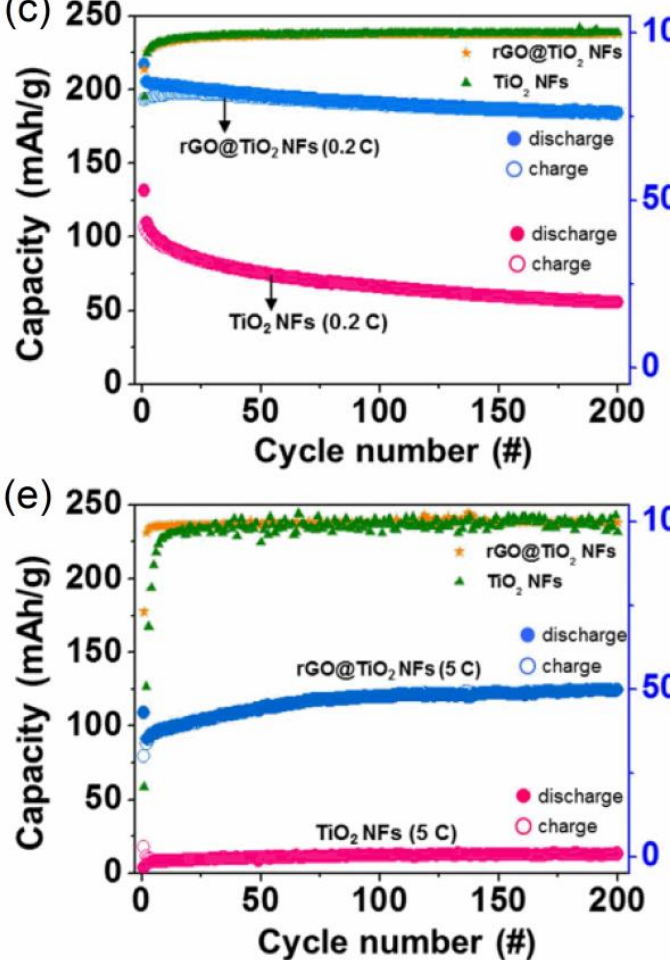

(d) 250
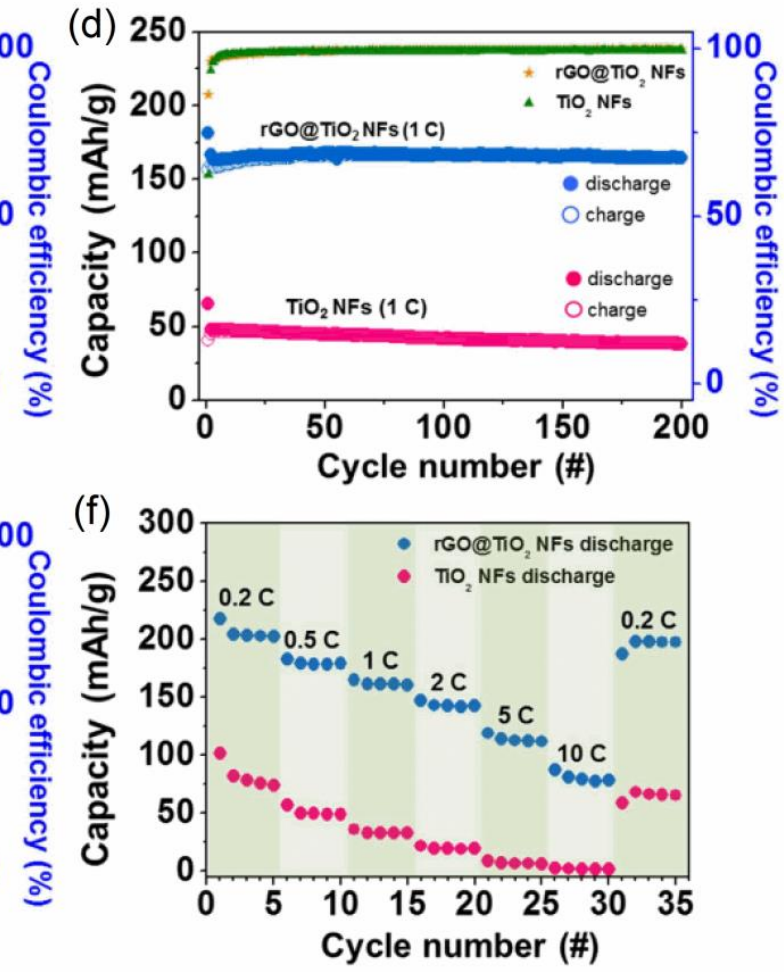

Figure 5. Schematic illustration of the synthesis of graphene- $\mathrm{TiO}_{2}$ NFs. (a) Products at each synthetic step, (b) graphene-wrapping mechanism; Charge-discharge capacity and coulombic efficiency vs. the cycle number for $\mathrm{TiO}_{2} \mathrm{NFs}$ and rGO@ $\mathrm{TiO}_{2} \mathrm{NFs}$ tested (c) at a rate of $0.2 \mathrm{C}\left(67 \mathrm{~mA} \mathrm{~g}^{-1}\right)$, (d) at a rate of $1 \mathrm{C}\left(335 \mathrm{~mA} \mathrm{~g}^{-1}\right)$, and (e) at a rate of $5 \mathrm{C}\left(1675 \mathrm{~mA} \mathrm{~g}{ }^{-1}\right)$, (f) Rate capabilities of $\mathrm{TiO}_{2} \mathrm{NFs}$ and $\mathrm{rGO} @ \mathrm{TiO}_{2} \mathrm{NFs}$ evaluated at various rates of 0.2 C, 0.5 C, 1 C, 2 C, 5 C, and 10 C. Reproduced with permission ${ }^{51}$. Copyright $\odot 2015$, Springer Nature.

Hollow structures have also been utilized to design $\mathrm{TiO}_{2}$ materials. Yang et al. designed $\mathrm{TiO}_{2} /$ carbon hollow spheres for the first time by using $\mathrm{SiO}_{2}$ as template, with dopamine used as carbon precursor in order to improve the electronic conductivity. SEM analysis showed that the hollow $\mathrm{TiO}_{2} /$ carbon nanospheres were around $100 \mathrm{~nm}$ in diameter, and carbon was uniformly distributed on the surface of each sphere. They designed this hollow structure (HS) 
because it could ensure good contact between the electrode and the electrolyte, facilitate fast transport of sodium ion/electrons, and withstand volume expansion, which led to improved electrochemical performance. The obtained $\mathrm{TiO}_{2} / \mathrm{C}$-HSs showed high reversible capacity of $140.4 \mathrm{~mA} \mathrm{~h} \mathrm{~g}^{-1}$ at $100 \mathrm{~mA} \mathrm{~g}^{-1}$ after 100 cycles, as well as remarkable rate performance, with capacity of 78.5 and $60.3 \mathrm{~mA} \mathrm{~h} \mathrm{~g}^{-1}$ at 1 and $2 \mathrm{~A} \mathrm{~g}^{-1}$, respectively ${ }^{54}$.

In addition, a yolk-shell $\mathrm{TiO}_{2} @ \mathrm{C}$ nanocomposite was designed by Qiu et al. They believed that it was important to control the morphology to prepare the carbon-coated $\mathrm{TiO}_{2}$ nanoparticles. There are several advantages for porous and hollow yolk-shell nanostructures, such as large contact area between the electrolyte and electrode, and short distances for ion diffusion, all of which benefit the electrochemical reaction kinetics in the electrode. Moreover, the yolk-shell nanoarchitecture is favourable for alleviating the structural strain, leading to a stable cycling performance. Most of the time, hollow structures with carbon frameworks can be fabricated by the conventional hydrothermal method, but, in this case, the metal salts and carbon precursors were mixed together, and the titanium salts would be easily hydrolyzed, so that it would be difficult to realize a homogeneous distribution of $\mathrm{TiO}_{2}$. In order to overcome this problem, a facile self-catalysed solvothermal method was used to synthesize the yolk-shell $\mathrm{TiO}_{2} @ \mathrm{C}$ microspheres, with $\mathrm{TiO}_{2}$ nanoparticles $(\sim 10 \mathrm{~nm})$ uniformly coated by furfural pyrolytic carbon. The size and structure of the $\mathrm{TiO}_{2}$ nanoparticles were controlled and aggregation was effectively prevented by carbon-coating.

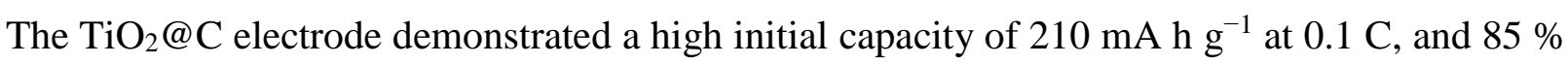
capacity retention was obtained after 2000 cycles at $1 \mathrm{C}$, as well as excellent rate capability, with $70 \mathrm{~mA} \mathrm{~g}^{-1}$ at $40 \mathrm{C}^{55}$. The improved electrochemical properties were mainly attributed to the unique yolk-shell structure that could enhance the electrical conductivity and accommodate the structural strain during sodiation/desodiation processes. Fig. 6 presents a schematic illustration of the preparation process, SEM and TEM images, and the electrochemical performance of these yolk-shell $\mathrm{TiO}_{2} @ \mathrm{C}$ microspheres. So far, designing nanosized $\mathrm{TiO}_{2}$ with carbon coating remains an effective way to improve its electrochemical performance $^{56}$. 


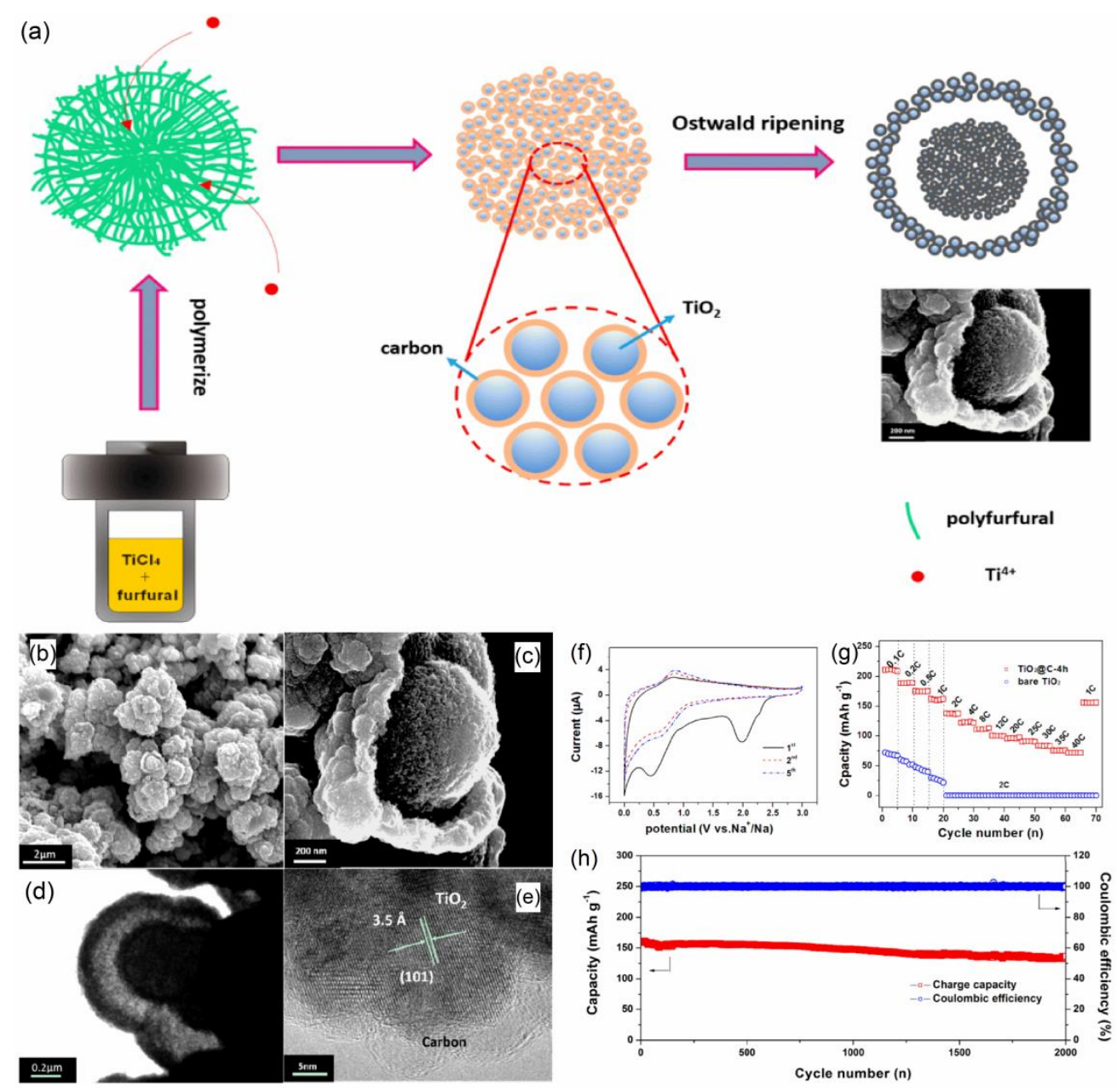

Figure 6. (a) Schematic illustration of the preparation process for the yolk-shell $\mathrm{TiO}_{2} @ \mathrm{C}$ microspheres. (b and c) SEM images, (d) TEM image, and (e) high-resolution TEM image of the hollow core-shell $\mathrm{TiO}_{2} @ \mathrm{C}-4 \mathrm{~h}$ microspheres; (f) $\mathrm{CV}$ curves at a scan rate of $0.1 \mathrm{mV} \mathrm{s}^{-1}$; (g) Rate performance at different rates from 0.1 to 40 $\mathrm{C}\left(1 \mathrm{C}=200 \mathrm{~mA} \mathrm{~g}^{-1}\right)$; (h) Long-term cycling performance at a charge-discharge current density of $1 \mathrm{C}$ (with the cell first cycled at $0.1 \mathrm{C}$ for 5 cycles and then cycled at $1 \mathrm{C}$ for 2000 cycles). Reproduced with permission ${ }^{55}$. Copyright $\odot$ 2017, American Chemical Society.

$\mathrm{Li}_{4} \mathrm{Ti}_{5} \mathrm{O}_{12}$ is an important anode material for LIBs due to its excellent cycling stability, which is considered as a kind of zero volume-change material. It also has been studied as a promising anode material for $\mathrm{SIBs}$ because $\mathrm{Li}_{4} \mathrm{Ti}_{5} \mathrm{O}_{12}$ can be a host for $\mathrm{Na}^{+}$insertion, according to a three-phase reaction. In previous works, most investigations on $\mathrm{Li}_{4} \mathrm{Ti}_{5} \mathrm{O}_{12}$ as anode material for SIBs related to fundamental research on such matters as structural evolution and phase transformation. More recently, researchers found that downsizing $\mathrm{Li}_{4} \mathrm{Ti}_{5} \mathrm{O}_{12}$ is an effective way to improve the sluggish $\mathrm{Na}^{+}$ion diffusion kinetics. In 2015, Hasegawa et al. designed a hierarchically nanostructured porous $\mathrm{Li}_{4} \mathrm{Ti}_{5} \mathrm{O}_{12}$ material with flower-like morphology as an anode material for SIBs. A sol-gel process accompanied by a spinodal decomposition method was used in the synthesis, and the influence of the 
calcination temperature was intensively studied ${ }^{57}$. Finally, the nanostructured $\mathrm{Li}_{4} \mathrm{Ti}_{5} \mathrm{O}_{12}$ electrodes (calcined at $700{ }^{\circ} \mathrm{C}$ ) exhibited high rate performance of $146 \mathrm{~mA} \mathrm{~h} \mathrm{~g}^{-1}$ and $105 \mathrm{~mA}$ $\mathrm{h} \mathrm{g}^{-1}$ at $10 \mathrm{C}$ and $30 \mathrm{C}$, respectively, and a capacity retention of $95 \%$ was achieved after 100 cycles at $1 \mathrm{C}$ (initial discharge capacity $=160 \mathrm{~mA} \mathrm{~h} \mathrm{~g}^{-1}$ ). The remarkable properties of this material can be attributed to the nanostructured crystallites that facilitate $\mathrm{Na}^{+}$transportation, the flowerlike morphology, and the porous structure, which increased the efficiency of electrode/electrolyte contact. The low electronic conductivity of $\mathrm{Li}_{4} \mathrm{Ti}_{5} \mathrm{O}_{12}$ is still a problem, however, that has impeded its practical application. For this reason, Chen and his co-workers designed and fabricated porous $\mathrm{Li}_{4} \mathrm{Ti}_{5} \mathrm{O}_{12}$ nanofibers wrapped with graphene (G-PLTO), and it showed a high capacity of $195 \mathrm{~mA} \mathrm{~h} \mathrm{~g}^{-1}$ at $0.2 \mathrm{C}$ and super-long cycle life up to 12000 cycles, which is the longest cycling performance reported for a titanium-based material so far 58 . This extraordinary performance can be ascribed to the porous nanostructure combined with graphene, which offers high electronic conductivity. The authors also focused their work on solid-liquid and solid-solid interfaces, because they thought that it could dramatically affect the sodium storage performance. Cyclic voltammetry (CV) and X-ray photoelectron spectroscopy (XPS) analysis confirmed that the sodium intercalation not only took place in the bulk of the $\mathrm{Li}_{4} \mathrm{Ti}_{5} \mathrm{O}_{12}$, but also at the interfaces of $\mathrm{Li}_{4} \mathrm{Ti}_{5} \mathrm{O}_{12}$ and graphene. Fig. 7 displays SEM images, a schematic illustration of $\mathrm{Na}$ storage, and the electrochemical performance of this G-PLTO. By designing a $\mathrm{Li}_{4} \mathrm{Ti}_{5} \mathrm{O}_{12}$ nanofibers@graphene composite with a unique structure, Na storage could take effect simultaneously in different places, which can lead to a new strategy for developing high-performance energy-storage performance. 

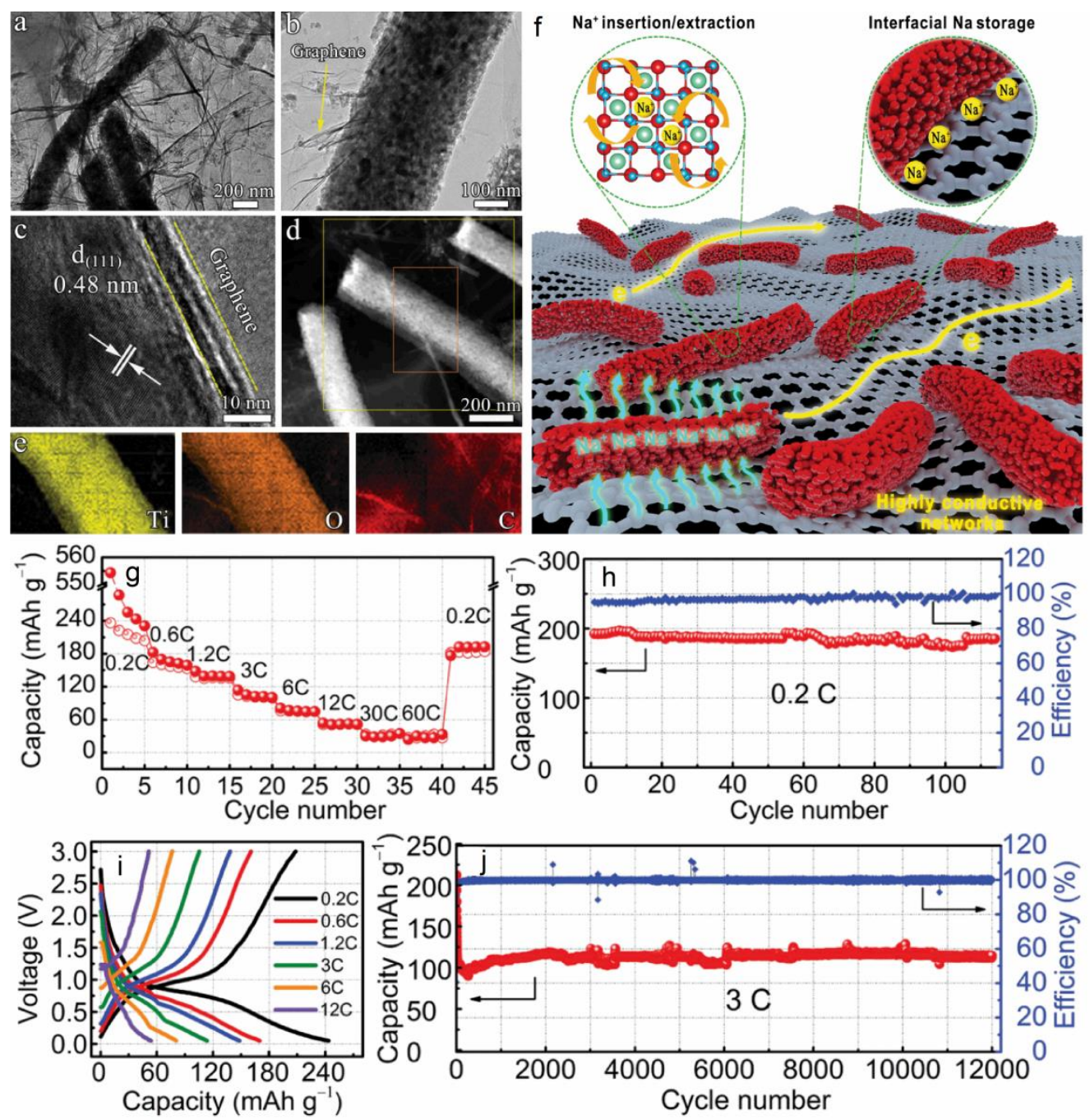

Figure 7. (a, b) TEM, (c) HR-TEM, and (d) STEM images, and (e) the corresponding Ti, O, and C element mapping images for the G-PLTO composite aerogel; (f) Graphical illustration of the structural merits and the integrated $\mathrm{Na}$ storage mechanisms in the G-PLTO electrode. Sodium storage performance of the G-PLTO electrode: $(\mathrm{g})$ rate performance at various $\mathrm{C}$-rates, (h) cycling performance at $0.2 \mathrm{C}$ after the rate performance test in (g), (i) charge-discharge profiles from various C-rates from 0.2-12 C, and (j) long-term cycling performance at $3 \mathrm{C}$ for 12000 cycles. Reproduced with permission ${ }^{58}$. Copyright $\odot 2016$ WILEY-VCH Verlag Gmbh \& Co. KGaA, Weinheim.

\subsection{Conversion materials and structural design}

Conversion type materials have been considered as potential anode materials for SIBs due to their high theoretical specific capacities. There are basically three groups of them including some transition metal oxide based anode materials, transition metal sulphides, and transition metal phosphides. Compared to insertion or alloying type anode materials, where $\mathrm{Na}^{+}$ions would easily be locked in or out of the bulk of the materials during charge/discharge processes, this would not happen for the conversion types of materials, because they could accommodate $\mathrm{Na}^{+}$ions through conversion reactions, which involve chemical transformation 
of atomic species, incorporating them into a host lattice to form a new compound. Nevertheless, the most serious problem for conversion type materials is the large volume expansion/contraction during the sodiation/desodiation processes, resulting in structural damage to the electrode and rapid capacity fading. In addition, the practical capacity for conversion materials is lower than the theoretical one because of the sluggish mobility of large $\mathrm{Na}^{+}$ions. It is worth noting, however, that some transition metal sulphides (e.g. $\mathrm{SnS}$ ) and most transition metal phosphides (eg. SnP, FeP, CoP) are capable of both conversion and alloying reactions. In this part, we mainly discuss some transition metal oxide and transition metal sulphide based materials as anode for SIBs. So far, much work has been done to overcome the problems of these conversion type materials, with most of them designed in nanostructured form combined with carbon coating, while porous structures and core-shell structures also can be seen in some cases.

\subsubsection{Transition metal oxides}

The first report on a transition metal oxide as anode material for SIBs involved $\mathrm{NiCo}_{2} \mathrm{O}_{4}{ }^{59}$. A reversible capacity of $\sim 200 \mathrm{~mA} \mathrm{~h} \mathrm{~g}{ }^{-1}$ was obtained based on coin cell testing, and even 300 $\mathrm{mA} \mathrm{h} \mathrm{g}{ }^{-1}$ was achieved when using $\mathrm{Na}_{x} \mathrm{CoO}_{2}$ as the cathode materials in the full cell. After that, a great many other transition metal oxides were investigated as anode materials for SIBs, such as iron oxides $\left(\mathrm{Fe}_{3} \mathrm{O}_{4}, \mathrm{Fe}_{2} \mathrm{O}_{3}\right){ }^{60,61}$, cobalt oxide $\left(\mathrm{Co}_{3} \mathrm{O}_{4}\right){ }^{62}$, tin oxides $\left(\mathrm{SnO}, \mathrm{SnO}_{2}\right)^{63-65}$, manganese oxide $(\mathrm{MnO}){ }^{66}$, copper oxide $(\mathrm{CuO})^{67}$, etc. ${ }^{68-74}$.

It is not uncommon to see excellent performance from transition metal oxide anode materials that consist of abundant nanosized transition metal oxide particles decorated by conductive materials, which is a similar method to the design of $\mathrm{TiO}_{2}$ materials as anode materials for SIBs. Wang et al. first reported a $\mathrm{SnO}_{2} @$ multiwalled carbon nanotube (MWCNT) nanocomposite as anode material for SIBs. A solvothermal method was utilized, and $\mathrm{SnO}_{2}$ nanoparticles were homogeneously distributed on the multiwall carbon nanotubes. The initial discharge capacity of this material was $839 \mathrm{~mA} \mathrm{~h} \mathrm{~g}^{-1}$, which demonstrates good sodium storage capability, and the cycling performance was also better than for any bare $\mathrm{SnO}_{2}$ or MWCNTs ${ }^{75}$. The same synthesis approach was also used in synthesizing $\mathrm{Co}_{3} \mathrm{O}_{4} @$ carbon nanotubes (CNTs). Jian et al. designed novel unique $\mathrm{Co}_{3} \mathrm{O}_{4}$ nanospheres with particle size of $\sim 200 \mathrm{~nm}$ and mixed them with carbon nanotubes. The as-prepared sample exhibited a reversible capacity of $487 \mathrm{~mA} \mathrm{~h} \mathrm{~g}^{-1}$, and a high capacity of $184 \mathrm{~mA} \mathrm{~h} \mathrm{~g}^{-1}$ was obtained at the high current density of $3200 \mathrm{~mA} \mathrm{~g}^{-1} 76$. Simply mixing a transition metal oxide with carbon materials could improve the electronic conductivity to some extent, but the 
structural expansion during cycling is still serious. A more complex carbon-confined $\mathrm{SnO}_{2}$ electrodeposited porous carbon nanofiber composite was fabricated by Dirican et al., and two kinds of carbon materials were used in this composite. Firstly, porous carbon nanofibers were used as template and $\mathrm{SnO}_{2}$ was deposited on them, and then the surface of the $\mathrm{SnO}_{2}$ was coated by carbon through the chemical vapour deposition (CVD) method. This complex structure could improve the electronic conductivity and stabilize the structure of $\mathrm{SnO}_{2}$ at the same time. Hence, this composite exhibited excellent electrochemical performance, including high-capacity (374 $\mathrm{mA} \mathrm{h} \mathrm{g}^{-1}$ ), good capacity retention $(82.7 \%$ ), and a high Coulombic efficiency $\left(98.9 \%\right.$ after the $100^{\text {th }}$ cycle) ${ }^{77}$. Another similar example was reported by Liu et al. They also used two kinds of carbon in a decoration method to fabricate $\mathrm{SnO}_{2} / \mathrm{C}$ materials, which displayed a high rate performance, with $342 \mathrm{~mA} \mathrm{~h} \mathrm{~g}^{-1}$ and a $144 \mathrm{~mA} \mathrm{~h} \mathrm{~g}^{-1}$ capacity at $10 \mathrm{C}$ and $30 \mathrm{C}$, respectively ${ }^{78}$. Apart from carbon fibers, graphene is another prevalent carbon material that has been utilized for synthesizing transition metal oxide/carbon composites. $\mathrm{Fe}_{2} \mathrm{O}_{3}{ }^{79,80}$ and $\mathrm{SnO}_{2}$ nanoparticles ${ }^{81}, \mathrm{MoO}_{3}$ nanosheets ${ }^{82}$, and many other transition oxides decorated with graphene have been studied, and they all show enhanced electrochemical performance, which is attributed to the small nanosized nature of the material, which can reduce the Na-ion diffusion distance, while carbon-coating could provide a continuous electronically conductive network.

Designing a mesoporous structure for a transition metal oxide is another effective approach to improving its electrochemical performance. It is accepted that the inherent properties of anode materials could directly affect the performance of the battery. Mesoporous structure inside a material could improve its energy density, cycling stability, and rate capability due to its large number of active sites, short sodium and electron diffusion paths, and of its ability to accommodate volume changes to some extent. Therefore, much work has been done on designing mesoporous transition metal oxides. For example, hierarchical mesoporous $\mathrm{SnO}$ microspheres were synthesized by Su et al. by a hydrothermal method. Field emission SEM (FESEM) testing demonstrated that the SnO microspheres consisted of nanosheets with a thickness of $\sim 20 \mathrm{~nm}$, with each nanosheet having a mesoporous structure with a pore size of $\sim 5 \mathrm{~nm}{ }^{83}$. Liu et al. also fabricated mesoporous $\mathrm{Co}_{3} \mathrm{O}_{4}$ sheets combined with graphene, and the average pore size in this $\mathrm{Co}_{3} \mathrm{O}_{4}$ was $\sim 3.8 \mathrm{~nm}$. The mesopores mainly originated from the aggregation of primary nanoparticles within a single $\mathrm{Co}_{3} \mathrm{O}_{4}$ mesoporous nanosheet (MNS), and void spaces between graphene nanosheets and the $\mathrm{Co}_{3} \mathrm{O}_{4}$ MNSs in the $3 \mathrm{D}$ network structure also contributed to the formation of 
microspores. The mesoporous structure of this material led to a stable cycling performance with capacity of $\sim 550 \mathrm{~mA} \mathrm{~h} \mathrm{~g}^{-1}$ and almost no capacity loss over 50 cycles ${ }^{84}$. Moreover, an aerosol spray pyrolysis technique was adopted to design a 3D porous $\gamma-\mathrm{Fe}_{2} \mathrm{O}_{3} @ \mathrm{C}$ nanocomposite. There were internally-connected nanochannels in the composite, and the $\gamma$ $\mathrm{Fe}_{2} \mathrm{O}_{3}$ nanoparticles $(5 \mathrm{~nm})$ were homogeneously distributed in the porous carbon matrix. This unique structure could offer synergistic effects to alleviate stress, accommodate large volume changes, prevent nanoparticle aggregation, and facilitate the transfer of electrons and electrolyte during prolonged cycling. Therefore, this material showed long cycling stability with a reversible capacity of $358 \mathrm{~mA} \mathrm{~h} \mathrm{~g}^{-1}$ over 1400 cycles at a high current density of 2000 $\mathrm{mA} \mathrm{g}^{-1} 85$.

There are also some transition metal oxides that have been designed with hollow structures. Jian et al. fabricated bowl-like $\mathrm{Co}_{3} \mathrm{O}_{4}$ microspheres by thermally treating a cobaltcontaining resorcinol-formaldehyde composite gel in air. SEM and TEM characterization demonstrated that there were hollow internal cavities inside these $\mathrm{Co}_{3} \mathrm{O}_{4}$ microspheres with multilayer outer shell walls (70 $\mathrm{nm}$ thickness). The sodium storage behaviour of hollowstructured $\mathrm{Co}_{3} \mathrm{O}_{4}$ was initially investigate, and it showed a high discharge capacity of $\sim 1400$ $\mathrm{mA} \mathrm{h} \mathrm{g}{ }^{-1}$ with retained capacity of $\sim 300 \mathrm{~mA} \mathrm{~h} \mathrm{~g}^{-1}$ after 10 cycles ${ }^{62}$. Another example is hollow structured $\mathrm{SnO}_{2} @ \mathrm{C}$ nanospheres, which were inspired by honeycombs. Dual templates were used to design the hollow structure, and glucose was utilized as the carbon coating source. The diameter of the hollow $\mathrm{SnO}_{2}$ nanopheres was 300-500 nm, and they were evenly encapsulated by a carbon shell. This structure could not only provide enough space to accommodate the volume changes, but also protected $\mathrm{SnO}_{2}$ from aggregation. Investigations of its electrochemical performance showed a stable cycling performance with a reversible capacity of $\sim 300 \mathrm{~mA} \mathrm{~h} \mathrm{~g}^{-1}$ over 100 cycles at $100 \mathrm{~mA} \mathrm{~g}^{-1}$, as well as a good rate performance, with capacity of $200 \mathrm{~mA} \mathrm{~h} \mathrm{~g}^{-1}$ at $100 \mathrm{~mA} \mathrm{~g}^{-1}$. A schematic illustration, SEM and TEM images, and the electrochemical performance of the hollow structured $\mathrm{SnO}_{2} @ \mathrm{C}$ nanospheres are displayed in Fig. 8. Some researchers, however, think that the subunits of the hollow structure may greatly affect the performance of a material. For instance, $\mathrm{Wu}$ and his co-workers fabricated $\alpha-\mathrm{Fe}_{2} \mathrm{O}_{3}$ multi-shelled core-shell microspheres, and the subunits of the structure were investigated. Two $\mathrm{Fe}_{2} \mathrm{O}_{3}$ core-shell samples were prepared using ethanol $\left(\mathrm{E}-\mathrm{Fe}_{2} \mathrm{O}_{3}\right)$ and water $\left(\mathrm{W}-\mathrm{Fe}_{2} \mathrm{O}_{3}\right)$, respectively. Compared to the ethanol sample with a normal core-shell structure, $\mathrm{W}-\mathrm{Fe}_{2} \mathrm{O}_{3}$ showed a core with smaller nanoparticles $\sim 50 \mathrm{~nm}$ in size, a thicker shell, and an exterior surface that featured porous nanorods. They concluded that the core-shell 
structure of $\mathrm{Fe}_{2} \mathrm{O}_{3}$ was dramatically affected by different solvents, and the subunit structure played an important role in the electrochemical performance. The $\mathrm{W}-\mathrm{Fe}_{2} \mathrm{O}_{3}$ had a higher specific surface area, greater pore volume, and more voids in small units, which provided a larger contact area for the electrolyte and helped to relieve the volume change strain in materials. Hence, the $\mathrm{W}-\mathrm{Fe}_{2} \mathrm{O}_{3}$ displayed better sodium storage performance and cycling stability, with capacities of $300 \mathrm{~mA} \mathrm{~h} \mathrm{~g}^{-1}$ and $150 \mathrm{~mA} \mathrm{~h} \mathrm{~g}^{-1}$ obtained after 80 and 100 cycles at 40 and $100 \mathrm{~mA} \mathrm{~g}^{-1}$, respectively ${ }^{86}$. In addition to the core-shell structure, designing transition metal oxides with yolk-shell structure could also buffer the volume changes more effectively due to its void space inside of the shells. Li et al. designed yolk-shell structured $\mathrm{SnO}_{2} @$ void@C porous nanowires through the $\mathrm{SiO}_{2}$ template method followed by carbon coating, with the $\mathrm{SiO}_{2}$ template removed by $\mathrm{NaOH}$ washing. TEM and FESEM showed that porous $\mathrm{SnO}_{2}$ nanowires were surrounded by carbon shells with tremendous void space, so that the composite exhibited a capacity of $401 \mathrm{~mA} \mathrm{~h} \mathrm{~g}^{-1}$ at $50 \mathrm{~mA} \mathrm{~g}^{-1}$ after 50 cycles and excellent rate performance with capacity of $\sim 220 \mathrm{~mA} \mathrm{~h} \mathrm{~g}^{-1}$ even at the high current density of $800 \mathrm{~mA} \mathrm{~g}^{-1} 87$.
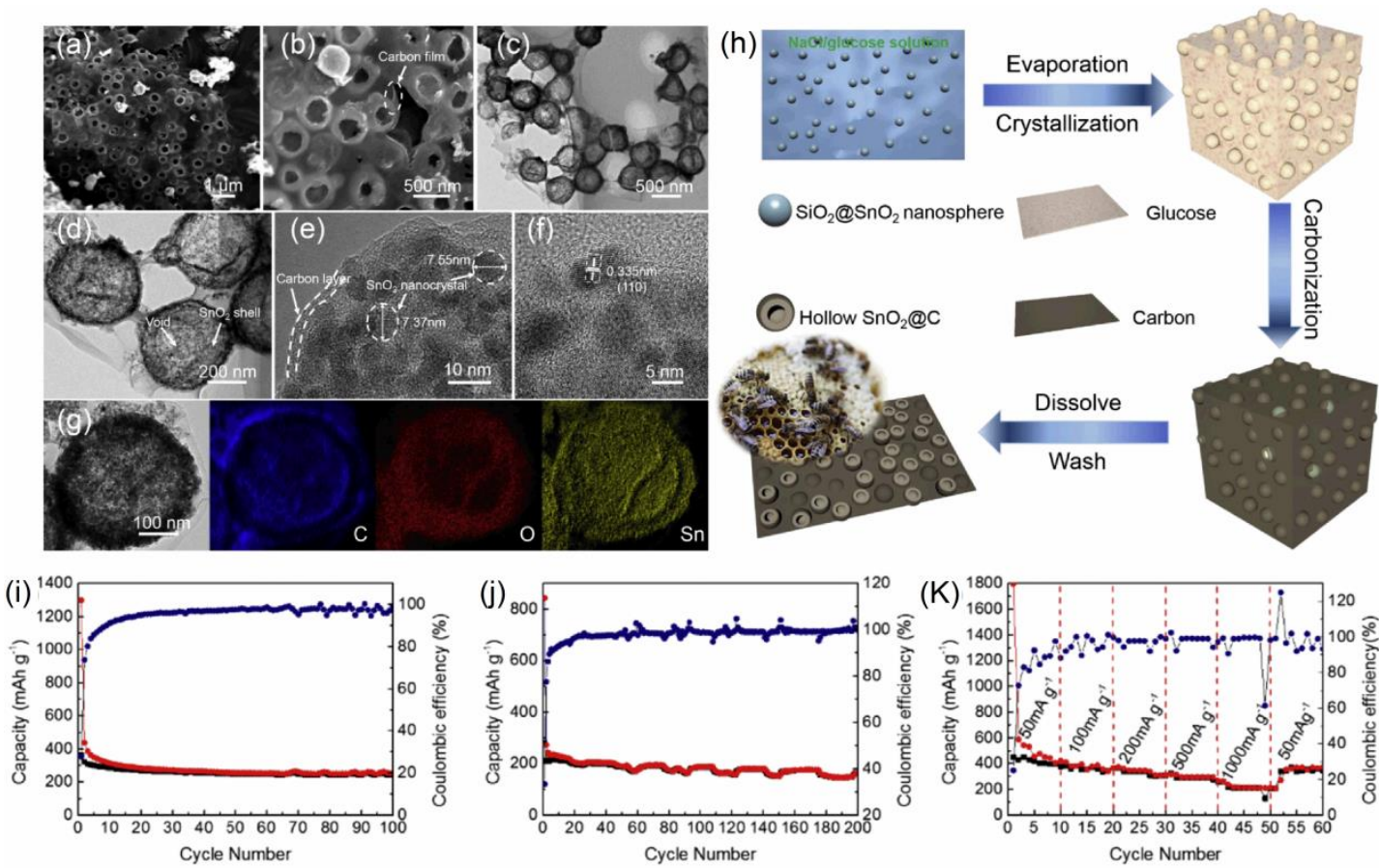

Figure 8. (a, b) SEM, (c, d) TEM, and (e, f) HRTEM images, and (g) EELS elemental mapping analysis images of honeycomb-like composites showing the element distributions; (h) Schematic illustration of the fabrication procedure for honeycomb-inspired $\mathrm{SnO}_{2} @ \mathrm{C}$ nanospheres embedded in carbon film; (i, j) Cycling performance and Coulombic efficiency of the honeycomb-like composites anodes in SIBs at current densities of $100 \mathrm{~mA} \mathrm{~g}^{-1}$ and $500 \mathrm{~mA} \mathrm{~g}^{-1}$, respectively; (k) Rate capabilities of the honeycomb-like composite anode for SIBs. Reproduced with permission ${ }^{64}$. Copyright (C) 2017 Elsevier B.V. All rights reserved. 


\subsubsection{Transition metal sulphides}

Compared to transition metal oxides as anode materials for SIBs, transition metal sulphides have also drawn researchers' attention due to their higher theoretical capacity. Moreover, the M-S bonds are weaker than M-O bonds (where $\mathrm{M}$ is a transition metal), which makes conversion reactions with $\mathrm{Na}^{+}$easier, and as a result, transition metal sulphide is normally more mechanically flexible and reversible during sodiation-desodiation processes. Various metal sulphides have been investigated as anode materials for SIBs, including $\mathrm{MoS}_{2}{ }^{88-100}$, $\mathrm{Sb}_{2} \mathrm{~S}_{3}{ }^{101-104}, \mathrm{SnS}_{2}{ }^{105-107}, \mathrm{WS}_{2}{ }^{108}$, etc.

Although many transition metal sulphides possess a layered structure that is favourable for $\mathrm{Na}^{+}$ion intercalation, however, much work has been done on designing nanostructured materials as with transition metal oxides. For example, $\mathrm{WS}_{2}$ nanowire was fabricated with a thin diameter of $25 \mathrm{~nm}$ and expanded interlayer spacing of $0.83 \mathrm{~nm}$. It demonstrated an ultralong cycling stability with capacity around $250 \mathrm{~mA} \mathrm{~h} \mathrm{~g}^{-1}$ at $1000 \mathrm{~mA} \mathrm{~g}^{-1}$ over 1400 cycles ${ }^{109}$. In addition, nanopheres ${ }^{110}$, nanosheets ${ }^{93}$, nanoflowers ${ }^{99}$ and nanofibers ${ }^{111}$ were also reported as well. There are many reports on $\mathrm{MoS}_{2}$ nanosheets combined with graphene as composite for SIBs due to their similar two-dimensional heterointerfaces. For instance, Xie et al. synthesized a $\mathrm{MoS}_{2} /$ Graphene composite through a facile one-pot hydrothermal method. They found that the heterointerfacial area was affected by the ratio of $\mathrm{MoS}_{2}$ to reduced graphene oxide (RGO), and it had an influence on the reversible capacity and electronic conductivity of $\mathrm{MoS}_{2} /$ Graphene composite. The composite showed the best electrochemical performance when the $\mathrm{MoS}_{2}$ weight ratio in the MG- $x$ composites was $68.7 \%$. These results offered a better fundamental understanding for the rational design of layered metal sulfide/graphene composites as high-performance electrode materials for sodium-ion batteries ${ }^{112}$. In a similar way, Liu et al. also designed exfoliated-SnS 2 restacked on graphene, so that the ultra-small $\mathrm{SnS}_{2}$ nanoplates composed of 2-5 layers were homogeneously decorated on the surfaces of the graphene, demonstrating a 3D network architecture. The obtained sample showed a stable cycling performance with capacity of $\sim 610 \mathrm{~mA} \mathrm{~h} \mathrm{~g}^{-1}$ over 300 cycles at 200 $\mathrm{mA} \mathrm{g}^{-1}$, which can be attributed to the unique structure of heterointerfaces between $\mathrm{SnS}_{2}$ and graphene that could suppress aggregation and volume fluctuation ${ }^{113}$.

Instead of investigating the interfaces of transition metal sulphides and graphene, another interesting structural design method for transition metal sulphides is to vertically grow them on carbon materials. For example, sandwich-like graphene@ $\mathrm{MoS}_{2} @ \mathrm{C}$ sheets were fabricated by Teng et al. The $\mathrm{MoS}_{2}$ nanosheets were perpendicularly connected with 
rGO through direct chemical coupling (C-O-Mo bonds), and the chemical bond could enhance the structural stability of the electrode. Meanwhile, the vertical nanostructure was able to improve the electrode reaction kinetics due to more active sites and short diffusion paths for $\mathrm{Na}^{+}$reactions. The carbon shell and graphene could also buffer the volume changes of $\mathrm{MoS}_{2}$ during cycling. The as-prepared sample showed excellent rate capability with capacity of $304 \mathrm{~mA} \mathrm{~h} \mathrm{~g}^{-1}$ after 200 cycles at $5 \mathrm{~A} \mathrm{~g}^{-1}$ and stable cycling performance $(260 \mathrm{~mA}$ $\mathrm{h} \mathrm{g}^{-1}$ after 300 cycles at $\left.10 \mathrm{~A} \mathrm{~g}^{-1}\right)^{114}$. Another example was reported by Xie et al. They also designed $\mathrm{MoS}_{2}$ nanosheets that were vertically aligned on carbon paper as a free standing electrode for SIBs. They believed that the hierarchical structure enables sufficient electrode/electrolyte interaction and fast electron transportation. Meanwhile, the unique architecture could enhance the initial coulombic efficiency through minimizing excessive interfaces between carbon and the electrolyte ${ }^{115}$.

Porous structures can be also used in designing transition metal sulphides. Cho el al. reported porous FeS nanofibers with numerous nanovoids as anode material for SIBs, which were prepared by electrospinning and subsequent sulfidation. Hollow $\mathrm{Fe}_{2} \mathrm{O}_{3}$ nanofibers were first prepared through annealing as-spun $\mathrm{Fe}(\mathrm{acac})_{3}$-polyacrylonitrile in air, and then, they was transformed into porous FeS by the sulfidation method. A schematic illustration, SEM and TEM images, and the electrochemical performance of this material are shown in Fig. 9. In comparison to hollow $\mathrm{Fe}_{2} \mathrm{O}_{3}$, the stable porous structure of $\mathrm{FeS}$ nanofiber displayed a stable cycling performance and high rate capability. The discharge capacity increased from 561 to $592 \mathrm{~mA} \mathrm{~h} \mathrm{~g}^{-1}$ during the first $150^{\text {th }}$ cycles, and high capacity of 380 and $353 \mathrm{~mA} \mathrm{~h} \mathrm{~g}^{-1}$ was achieved even at 3 and $5 \mathrm{~A} \mathrm{~g}^{-1}$, respectively ${ }^{116}$. Another case study of $3 \mathrm{D}$ porous interconnected $\mathrm{WS}_{2} / \mathrm{C}$ was reported by Zhu et al., where an electrostatic spray deposition technique was used to create the porous structure. This $3 \mathrm{D}$ porous $\mathrm{WS}_{2} / \mathrm{C}$ composite exhibited high rate capability $\left(400,270,199\right.$, and $81 \mathrm{~mA} \mathrm{~h} \mathrm{~g}^{-1}$ at $0.2,1,2$, and $10 \mathrm{C}$, respectively) and stable cycling performance (219 $\mathrm{mA} \mathrm{h} \mathrm{g}^{-1}$ at $1 \mathrm{C}$ after 300 cycles). This excellent performance can be attributed to the 3D porous structure, which could improve electron diffusion, buffer the volume change during cycling, and increase the contact area with the electrolyte, which ensures fast $\mathrm{Na}$ ion transport ${ }^{117}$. 

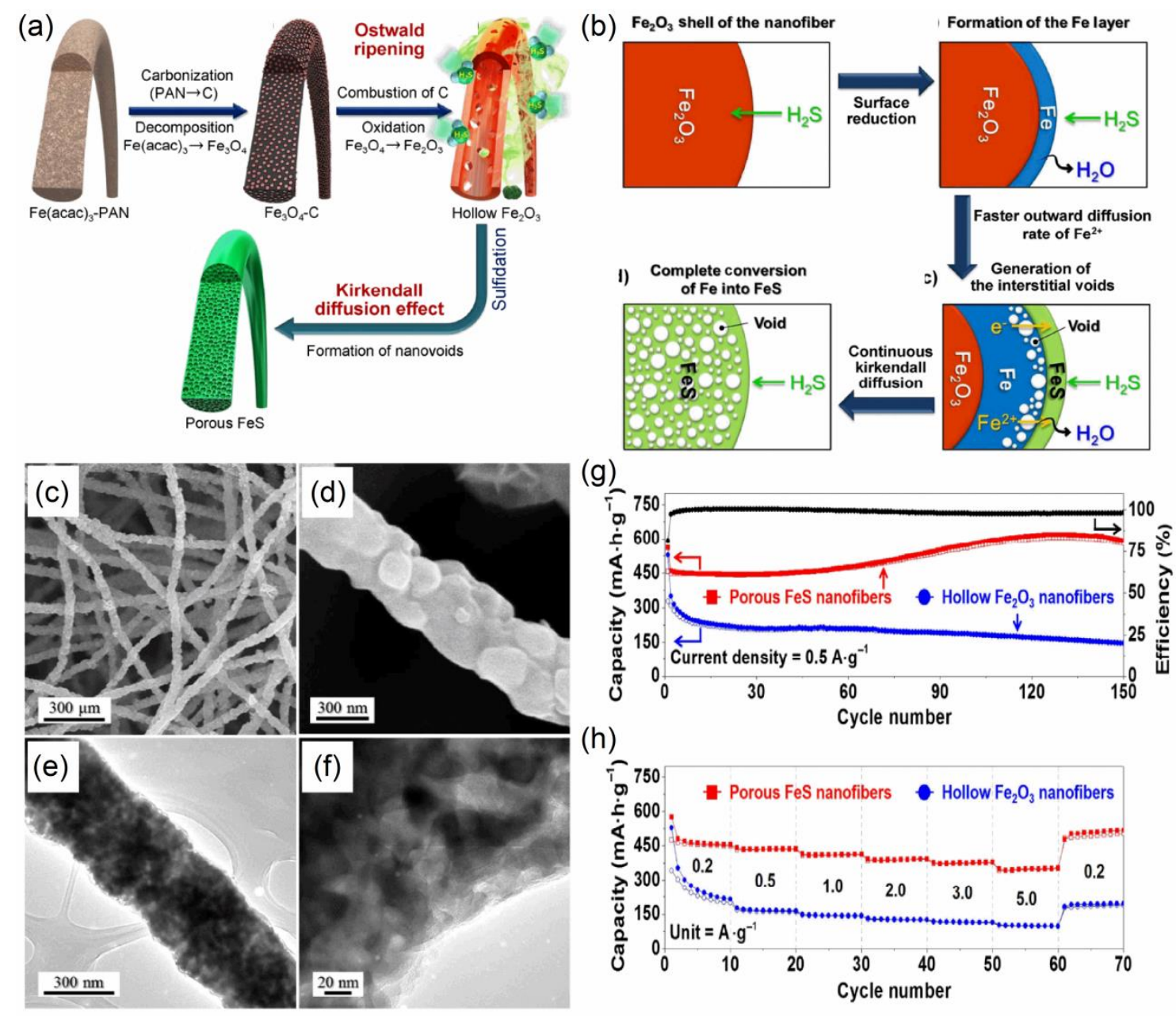

Figure. 9 (a) Formation mechanism of the porous FeS nanofibers with numerous nanovoids; (b) Detailed mechanism for the formation of nanovoids in the surface region of the $\mathrm{Fe}_{2} \mathrm{O}_{3}$ shell of the nanofibers by nanoscale Kirkendall diffusion; (c, d) SEM and (e, f) TEM images of the porous FeS nanofibers containing numerous nanovoids after sulfidation at $400{ }^{\circ} \mathrm{C}$ for $8 \mathrm{~h}$; (g) Cycling performance at a constant current density of $500 \mathrm{~mA} \mathrm{~g}^{-1}$, and (h) rate performance at different current densities of porous $\mathrm{FeS}$ and hollow $\mathrm{Fe}_{2} \mathrm{O}_{3}$ nanofibers for sodium-ion storage. Reproduced with permission ${ }^{116}$. Copyright $($ C 2016, Springer Nature.

The fabrication of core-shell structure is another effective approach to designing transition metal sulphides. Wang et al. synthesized a composite of core-shell $\mathrm{MoS}_{2} / \mathrm{C}$ nanospheres embedded in foam-like sheets, and it showed high capacity and stable cycling performance. The $\mathrm{MoS}_{2}$ core was fabricated by using $\mathrm{NaCl}$ and $\mathrm{SiO}_{2}$ as templates, while the carbon shell and the carbon sheets came from glucose carbonization. There are many spaces between $\mathrm{MoS}_{2}$ nanospheres that could buffer the volume changes and provide fast transport of $\mathrm{Na}^{+}$ions, while the carbon shell could also enhance the electronic conductivity and suppress the aggregation of $\mathrm{MoS}_{2}$ as well. As a result, the as-prepared sample displayed a high discharge capacity of $523 \mathrm{~mA} \mathrm{~h} \mathrm{~g}^{-1}$ after 100 cycles at $0.1 \mathrm{~A} \mathrm{~g}^{-1}$, and a capacity of 337 $\mathrm{mA} \mathrm{h} \mathrm{g}{ }^{-1}$ could be obtained after the $300^{\text {th }}$ cycle, even at $1 \mathrm{~A} \mathrm{~g}^{-1}{ }^{110}$. In addition, a more 


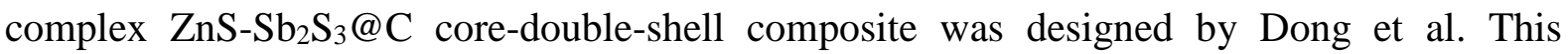
special structure was derived from a metal-organic framework. The $\mathrm{ZnS}$ inner core was surrounded by a $\mathrm{Sb}_{2} \mathrm{~S}_{3} @ \mathrm{C}$ double-shell, and the composite demonstrated an excellent electrochemical performance. A reversible capacity of $\sim 600 \mathrm{~mA} \mathrm{~h} \mathrm{~g}^{-1}$ was obtained after 120 cycles at $100 \mathrm{~mA} \mathrm{~g}^{-1}$, and $\sim 300 \mathrm{~mA} \mathrm{~h} \mathrm{~g}^{-1}$ can be achieved even at a high current density of $800 \mathrm{~mA} \mathrm{~g}^{-1}$. The outstanding performance can be attributed to the unique core-shell structure, which not only facilitates facile electrolyte infiltration to reduce the Na-ion diffusion length and improve the electrochemical reaction kinetics, but also protects the structure from pulverization caused by Na-ion insertion/extraction ${ }^{118}$.

\subsection{Alloy based materials and structural design}

Similar to the conversion type materials, alloy based materials are also promising candidates for SIB anode because they can accommodate a great number of sodium ions in the host structure at an operating voltage below $1.0 \mathrm{~V}$, and high specific capacities could be achieved during multiple alloying-dealloying reactions between sodium and the metals. To date, group 14 and 15 elements in the periodic table have been widely investigated as potential anode materials for SIBs. Nevertheless, the large $\mathrm{Na}^{+}$ions still cause huge volume changes during the repeated alloying-dealloying reactions, ultimately leading to fracturing or pulverization of the electrode and capacity fade. Many desirable architectures and enhanced electrode designs have been investigated, but in this part, we mainly discuss the structural design of alloy based materials containing group 14 and 15 elements.

\subsubsection{Alloying compounds in group 14}

Many investigations related to group 14 in the periodic table elements have been focused on germanium (Ge) and tin ( $\mathrm{Sn}$ ) due to their high theoretical capacity of 369 and $847 \mathrm{~mA} \mathrm{~h} \mathrm{~g}{ }^{-1}$, respectively ${ }^{119-128}$. Researchers have found that the particle size of alloy based materials is vitally important for their electrochemical performance, and therefore, many nanostructured alloy based materials have been designed. For example, Seng et al. synthesized Ge nanoparticles through a facile self-assembly method, in which the Ge particles are located inside the carbon shell. The as-prepared sample displays a stable cycling performance and excellent rate capability. The capacity remains at $\sim 900 \mathrm{~mA} \mathrm{~h} \mathrm{~g}^{-1}$ over 120 cycles when charged and discharged at 1.6 and $0.8 \mathrm{~A} \mathrm{~g}^{-1}$ respectively, and capacities of $\sim 750$ and $450 \mathrm{~mA}$ $\mathrm{h} \mathrm{g}^{-1}$ could be observed even at 30 and $40 \mathrm{C}$ respectively. They concluded that the superior electrochemical performance of their material could be ascribed to the unique nanostructure, which provides good electrolyte diffusion into/out of the pores and high electronic 
conductivity via the carbon shells ${ }^{129}$. Another example relates to the ultra-small Sn nanodots designed by Ying et al. through a simple spray-drying process. In order to improve the cycling performance, they also introduced $\mathrm{N}$-doped carbon microcages (NMCs) to form a composite with the Sn nanodots. Electrochemical tests showed that the Sn/NMCs could deliver an initial reversible capacity of $439 \mathrm{~mA} \mathrm{~h} \mathrm{~g}^{-1}$ at $50 \mathrm{~mA} \mathrm{~g}^{-1}$ and retain $332 \mathrm{~mA} \mathrm{~h} \mathrm{~g}^{-1}$ after 300 cycles ${ }^{130}$. Similar to this, there are also some other types of composites of carbon materials with nanosized Sn that have been reported, such as Sn@CNT 131, Sn@Porous carbon ${ }^{132}$, etc. Thanks to the nanostructure and improved electronic conductivity, all of them exhibited wonderful electrochemical performances.

In addition to the investigation of single element alloy based materials in group 14, some binary alloy materials also have drawn attention, and many nanostructured materials have been designed. $\mathrm{SnSb} / \mathrm{C}$ nanocomposites were first studied by Xiao et al. The sample was prepared by high-energy mechanical milling under an argon atmosphere and energy dispersive spectroscopy (EDS) analysis demonstrated that the $\mathrm{Sn}$ and $\mathrm{Sb}$ elements were distributed homogeneously (ratio of $\mathrm{Sn} / \mathrm{Sb}=1: 1$ ). The electrode could achieve an exceptionally high capacity of $544 \mathrm{~mA} \mathrm{~h} \mathrm{~g}^{-1}$, good rate capacity, and good cyclability (80\% capacity retention over 50 cycles) for Na-ion storage ${ }^{133}$. A Sn-Cu nanocomposite $\left(\mathrm{Sn}_{0.9} \mathrm{Cu}_{0.1}\right)$ was also fabricated by Lin et al. through a simple wet chemical method, and the nanoparticlebased electrodes exhibited a stable capacity greater than $420 \mathrm{~mA} \mathrm{~h} \mathrm{~g}^{-1}$ at the $0.2 \mathrm{C}$ rate, with $97 \%$ of the capacity retained after 100 cycles ${ }^{134}$. Zhang et al. also synthesized a SnSe/carbon nanocomposite via a high-energy ball-milling method. An initial capacity of $748.5 \mathrm{~mA} \mathrm{~h} \mathrm{~g}{ }^{-1}$ was obtained, and a capacity of $324.9 \mathrm{~mA} \mathrm{~h} \mathrm{~g}^{-1}$ could be observed at $500 \mathrm{~mA} \mathrm{~g}^{-1}$ after 200 cycles ${ }^{135}$.

In addition to the normal nanostructured design of alloying compounds in group 14, $\mathrm{Li}$ et al. also created a yolk-shell Sn@C nanostructured material inspired by a famous HongKong snack: eggette. From the shape of the snack, they thought that the $\mathrm{SnO}_{2}$ nanospheres could be wrapped in a carbon layer and distributed on carbon sheets. To be more specific, hollow $\mathrm{SnO}_{2}$ nanoparticles were first synthesized by using $\mathrm{NaCl}$ as template, and then the yolk-shell Sn@C was formed by glucose reduction and carbonization. The yolk-shell structure was designed to buffer the large volume expansion during cycling, while the carbon sheet acts as an electron-conducting network and could suppress aggregation of $\mathrm{Sn}$ particles at the same time. As a result, the yolk-shell Sn@C material exhibits superior rate performance, with capacity of $\sim 200 \mathrm{~mA} \mathrm{~h} \mathrm{~g}^{-1}$ at the high current density of $5000 \mathrm{~mA} \mathrm{~g}^{-1}$. In 
terms of the cycling performance, the capacity still remained at $\sim 200 \mathrm{~mA} \mathrm{~h} \mathrm{~g}^{-1}$ after 1000 cycles ${ }^{136}$.

\subsubsection{Alloying compounds in group 15}

Most work on elements in group 15 has been related to antimony ( $\mathrm{Sb}$ ) and phosphorus $(\mathrm{P})$ because of their high theoretical capacity, with 660 and $2596 \mathrm{~mA} \mathrm{~h} \mathrm{~g}^{-1}$, respectively. The same as with alloy compounds in group 14, however, the huge volume expansion/contraction is still the main problem. There are many similar structural designs for alloying compounds in group 15.

Many investigations on single element based materials in group $15^{137-142}$ have been related to nanostructure fabrication ${ }^{143,144}$. Liang et al. designed highly ordered Sb nanorod arrays as anode material for SIBs with uniform large interval spacing (190 nm). This structural design presents many advantages, such as high ion accessibility, fast electron transport, and strong electrode integrity. This material demonstrated a high capacity of 620 $\mathrm{mA} \mathrm{h} \mathrm{g}{ }^{-1}$ at the $100^{\text {th }}$ cycle with capacity retention of $84 \%$, even at 10 and $20 \mathrm{~A} \mathrm{~g}^{-1}$, and reversible capacities of 579.7 and $557.7 \mathrm{~mA} \mathrm{~h} \mathrm{~g}^{-1}$ could be achieved, respectively ${ }^{145}$. Carbon materials are often introduced into the materials synthesis process in order to enhance the electronic conductivity. Luo et al. fabricated $\mathrm{Sb}$ nanoparticles anchored on a 3D carbon network through a template-assisted self-assembly method, followed by freeze-drying and carbonization. This composite delivered a high reversible capacity $\left(456 \mathrm{~mA} \mathrm{~h} \mathrm{~g}^{-1}\right.$ at $100 \mathrm{~mA}$ $\mathrm{g}^{-1}$ ), and $94.3 \%$ capacity retention was obtained after 500 cycles at $100 \mathrm{~mA} \mathrm{~g}^{-1}$, as well as superior rate capability $\left(270 \mathrm{~mA} \mathrm{~h} \mathrm{~g}^{-1} \text { at } 2000 \mathrm{~mA} \mathrm{~g}^{-1}\right)^{146}$. Zhang also synthesized a spherical nano-Sb@C composite by an aerosol spray pyrolysis technique, resulting in small $\mathrm{Sb}$ particles with diameters of about $10 \mathrm{~nm}$. This composite provided a discharge capacity of $435 \mathrm{~mA} \mathrm{~h} \mathrm{~g}^{-1}$ in the second cycle and $385 \mathrm{~mA} \mathrm{~h} \mathrm{~g}^{-1}$ after 500 cycles at $100 \mathrm{~mA} \mathrm{~h} \mathrm{~g}^{-1}$, with high capacity retention of $88.5 \%{ }^{147}$. Moreover, Sb-C nanotubes ${ }^{148}$ and Sb-C nanofibers ${ }^{149}$, ${ }^{150}$ have also been investigated.

Similar to Sb based materials, nanostructured forms of phosphorus have been designed as well. $\mathrm{Xu}$ et al. fabricated nanostructured black phosphorus and mixed it with Ketjenblack and multiwalled carbon nanotubes through a high energy ball-milling method. The asprepared sample displayed a very high initial Coulombic efficiency (> $90 \%$ ), and a capacity of $\sim 1700 \mathrm{~mA} \mathrm{~h} \mathrm{~g}^{-1}$ also can be observed after 100 cycles at a high current density of $1.3 \mathrm{~A} \mathrm{~g}^{-1}$ 151. In addition, Sun et al. used the same method to synthesize a composite of black 
phosphorus nanoparticles and graphite, and the chemical bonds between the phosphorus and the carbon were investigated by ab initio density functional theory. The results showed that graphite is the best carbon material for stabilizing P-C bonds in phosphorus-nanoparticlescarbon composite, which could enable a long cycle life and high-rate capability. Therefore, it is not surprising that a reversible capacity of $2000 \mathrm{~mA} \mathrm{~h} \mathrm{~g}^{-1}$ was obtained after 100 cycles at $0.2 \mathrm{C}$, and $1300 \mathrm{~mA} \mathrm{~h} \mathrm{~g}^{-1}$ could be also observed at a high current density of $4.5 \mathrm{C}^{152}$. There are also some other kinds of composites of carbon materials with nanosized phosphorus that have been reported, such as with graphene ${ }^{153}$ and mesoporous carbon matrix ${ }^{154}$, where superior electrochemical performances were obtained as well.

Apart from fabricating single element materials in nanostructured form, many other advanced structural design approaches can be seen in alloying compounds from group 15 elements, including some binary or ternary alloy based materials, such as $\mathrm{NiSb}^{155}, \mathrm{Sn}_{5} \mathrm{SbP}_{3}$ ${ }^{156}, \mathrm{CoP}^{157}, \mathrm{FeP}^{158}, \mathrm{Sn}_{4} \mathrm{P}_{3}{ }^{159}$, etc. Some of them were designed in nanostructured form, and some of them were just decorated with carbon materials without any special structure. Here, we basically discuss some advanced structural designs for both single- and multi-phase based materials and their superior electrochemical performance.

Liu et al. fabricated a nanoporous (NP)-Sb anode for SIBs through chemical dealloying of Al-Sb alloy ribbon, and the morphology of $\mathrm{Sb}$ was controlled. Different ratios of Al-Sb alloy composition were investigated, and the different ratios gave the porous structures different morphology. The coral-like NP-Sb 70 (from dealloying of $\mathrm{Al}_{30} \mathrm{Sb}_{70}$ ) delivered the best electrochemical properties. It exhibited a high capacity of $573.8 \mathrm{~mA} \mathrm{~h} \mathrm{~g}^{-1}$ after 200 cycles at $100 \mathrm{~mA} \mathrm{~g}^{-1}$, and there was still a high capacity of over $400 \mathrm{~mA} \mathrm{~h} \mathrm{~g}^{-1}$ at a high current density of $3300 \mathrm{~mA} \mathrm{~g}^{-1}$. The excellent electrochemical performance was due to its innovative porous structure, which ensures strong structural integrity, high sodium ion accessibility, and fast electrode transport ${ }^{160}$. In addition, porous $\mathrm{Sb} / \mathrm{Cu}_{2} \mathrm{Sb}$ with $3 \mathrm{D}$ structure was designed by $\mathrm{Nam}$ et al. through electrodeposition on a $\mathrm{Cu}$ foam substrate. From SEM analysis, it has a three-dimensional porous structure with an apparent pore size of $\sim 10 \mathrm{~mm}$ and an average wall thickness of $\sim 5 \mathrm{~mm}$. The $\mathrm{Sb} / \mathrm{Cu}_{2} \mathrm{Sb}$ electrode exhibited outstanding cycling stability and excellent rate capability as well. A charge capacity of $485.64 \mathrm{~mA} \mathrm{~h} \mathrm{~g}^{-1}$ could be obtained after 120 cycles, along with a high coulombic efficiency of $\sim 97 \%$. Furthermore, the capacity still remained at $\sim 400 \mathrm{~mA} \mathrm{~h} \mathrm{~g}^{-1}$ at a high current density of $3 \mathrm{C}$, (with about $70 \%$ of the capacity retained at a $0.1 \mathrm{C}$ rate). The excellent electrochemical performance can be attributed to the porous structure, which could accommodate the 
volumetric expansion of the $\mathrm{Sb}$ and effectively inhibit the delamination of the anode materials ${ }^{161}$. Sun et al. also fabricated a red phosphorus@3D porous carbon composite through a carbothermic reduction method, in which $\mathrm{P}_{4} \mathrm{O}_{10}$ was used as the template to create the 3D structure by dehydrating polyethylene glycol (PEG), and also acted as the P source via carbothermic reduction. Through this method, the ultrafine red phosphorus particles $(\sim 10 \mathrm{~nm})$ were embedded in a 3D carbon framework with numerous interconnected nanopores. Fig. 10 schematically illustrates the structural design, and presents SEM images and the electrochemical performance of this P@3D porous carbon composite. As can be seen, it delivers a capacity of $920 \mathrm{~mA} \mathrm{~h} \mathrm{~g}^{-1}$ at the $160^{\text {th }}$ cycle with high capacity retention of $88 \%$. This superb electrochemical performance can be ascribed to red-P nanoparticles, which could shorten the $\mathrm{Na}^{+}$diffusion length, as well as the 3D porous carbon framework that not only functions as an electrical highway in which sodium ions and electrolyte can be transported, but also provides buffer space allowing the P particles to expand ${ }^{162}$.
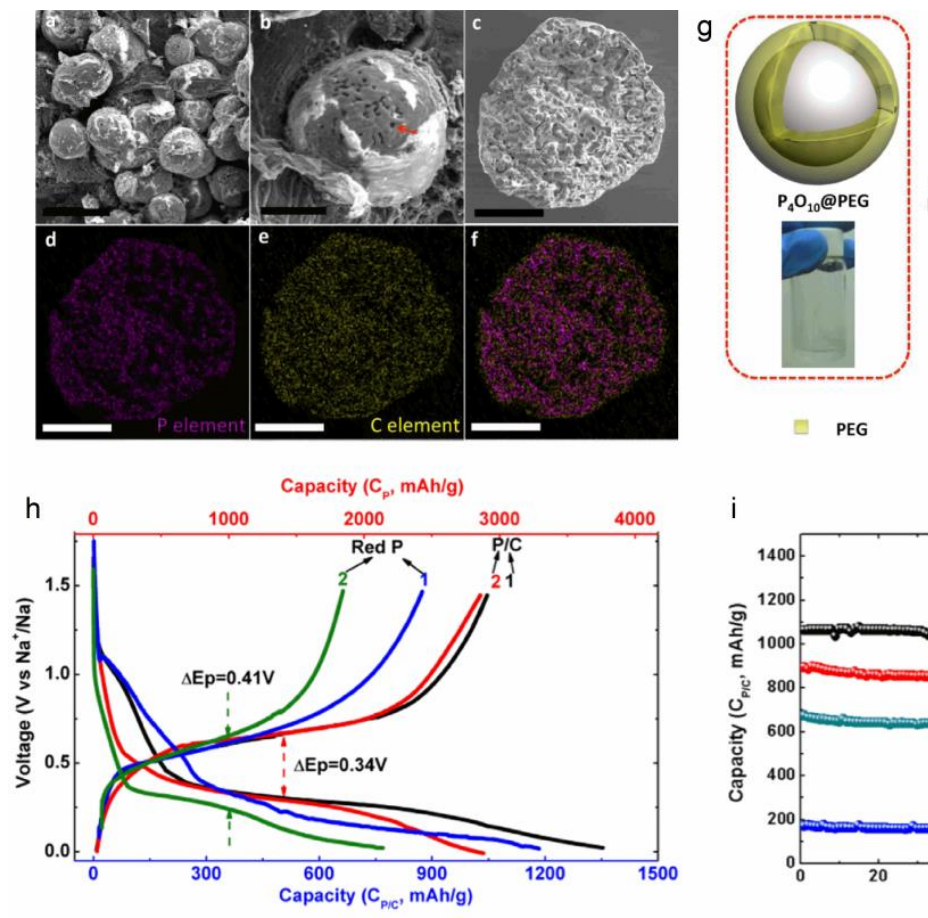

- 1 PEG

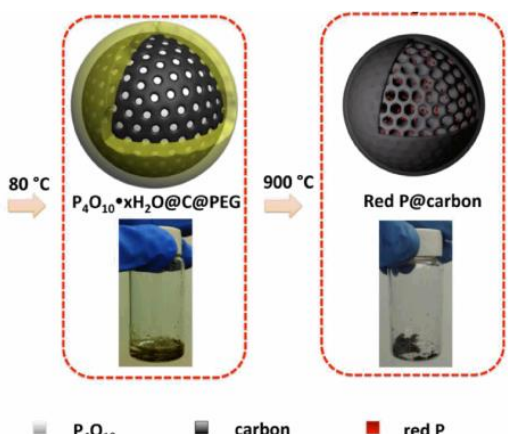

i

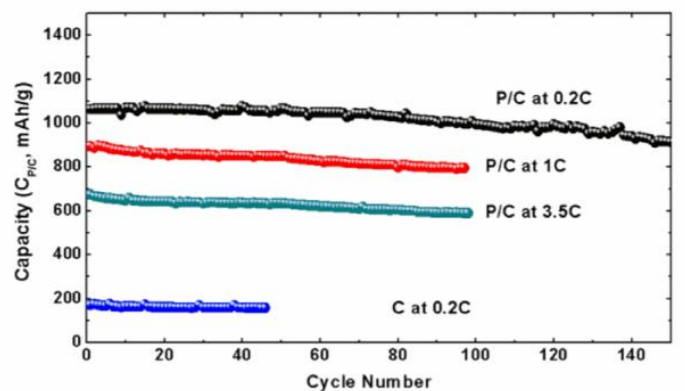

Figure 10. SEM and TEM characterization of the P/C composite: (a) low magnification SEM image (Scale bar, $20 \mu \mathrm{m}$ ), (b) high magnification SEM image of a single sphere (Scale bar, $10 \mu \mathrm{m}$ ), (c) SEM image of a cracked $\mathrm{P} / \mathrm{C}$ sphere (Scale bar, $10 \mu \mathrm{m}$ ), and the corresponding EDS elemental dot-mapping images of (d) P, (e) C, and (f) overlay of C and P (Scale bar, $10 \mu \mathrm{m}$ ); (g) Schematic illustration and digital photographs of the synthesis procedure for the ultrafine red phosphorus particles embedded in a 3D carbon framework (P/C composite); (h) Galvanostatic charge-discharge profiles of red $\mathrm{P}$ and $\mathrm{P} / \mathrm{C}$ electrodes for the first two cycles between 0.01 and 1.5 $\mathrm{V}$ with a current density of $0.2 \mathrm{C}$; (i) Cycling performance of the carbon framework alone and the P/C 
composite at different current densities of $0.2 \mathrm{C}, 1 \mathrm{C}$, and 3.5 C. Reproduced with permission ${ }^{162}$. Copyright $($ ) 2016 Published by Elsevier B.V.

Hollow structures can be also seen in some alloy based materials in group 15. Liu et al. synthesized 3D Ni/Sb intermetallic hollow nanospheres as anode material for high rate SIBs. The 3D interconnected hollow structures and Ni matrix encapsulation play important roles in stabilizing the structure of this Sb based material. Therefore, it exhibited good cycling stability with discharge capacities of 400,372 , and $230 \mathrm{~mA} \mathrm{~h} \mathrm{~g}^{-1}$ after 150 cycles at $1 \mathrm{C}, 5 \mathrm{C}$, and $10 \mathrm{C}$, respectively ${ }^{155}$. In addition, Zhou et al. fabricated hollow red-phosphorus nanospheres with porous shells, and this was considered as an ideal structure to resolve the problem of the large volume expansion of P. A wet solvothermal method was used and accompanied by a gas-bubble-directed formation mechanism. By taking advantages of both hollow and porous structure, the as-prepared sample demonstrated an initial capacity of $2274.5 \mathrm{~mA} \mathrm{~h} \mathrm{~g}^{-1}$ with high Coulombic efficiency of $77.3 \%$, as well as stable cycling performance with capacity of $969.8 \mathrm{~mA} \mathrm{~h} \mathrm{~g}^{-1}$ at $1 \mathrm{C}$ over 600 cycles ${ }^{163}$.

Core-shell structures also have been designed for some alloy based materials in group 15 because they could provide enough cushion space for volume changes, as well as shortening the $\mathrm{Na}^{+}$ion diffusion paths. For instance, Ge et al. fabricated porous core/shell CoP@C polyhedra and combined them with graphene, which was derived from zeolitic imidazolate framework-67 (ZIF-67) via a low-temperature phosphidation process. The as-prepared sample could deliver a specific capacity of $473.1 \mathrm{~mA} \mathrm{~h} \mathrm{~g}^{-1}$ at a current density of $100 \mathrm{~mA} \mathrm{~g}^{-1}$ after 100 cycles. The superior electrochemical performance can be attributed to the core/shell structure, which could provide a large electrode/electrolyte contact area and shorten the $\mathrm{Na}^{+}$ ion diffusion paths, while the volume change was suppressed by the carbon shell and the electronic conductivity was also enhanced dramatically by both the carbon shell and the graphene ${ }^{164}$. Another example relates to core-shell structured $\mathrm{CoP} / \mathrm{FeP}$ porous microcubes, which was synthesized through a low-temperature phosphorization process using Prussian blue as reactant template, and the microcubes were also interconnected by reduced graphene oxide to improve the electronic conductivity. SEM and TEM observations demonstrated that the $\mathrm{FeP}$ particles were covered by carbon layers and that all the $\mathrm{C}-\mathrm{FeP}$ particles were distributed inside of the CoP shell. Fig. 11 provides a schematic illustration and shows the morphology and electrochemical performance of the as-prepared material. Because of its unique core-shell structure, it displays a stable cycling performance and high rate capability. The capacity remains at $\sim 500 \mathrm{~mA} \mathrm{~h} \mathrm{~g}^{-1}$ after 200 cycles at $100 \mathrm{~mA} \mathrm{~g}^{-1}$, and there is still a 
capacity of $341.2 \mathrm{~mA} \mathrm{~h} \mathrm{~g}^{-1}$ even at the high current density of $2 \mathrm{~A} \mathrm{~g}^{-1}{ }^{157}$. In addition, Liu et al. also fabricated a red phosphorus@Ni-P material with core-shell nanostructures. It exhibited an ultra-long stable cycling performance, and a capacity of $409.01 \mathrm{~mA} \mathrm{~h} \mathrm{~g}^{-1}$ could be obtained after 2000 cycles at the high current density of $5 \mathrm{~A} \mathrm{~g}^{-1} 165$.
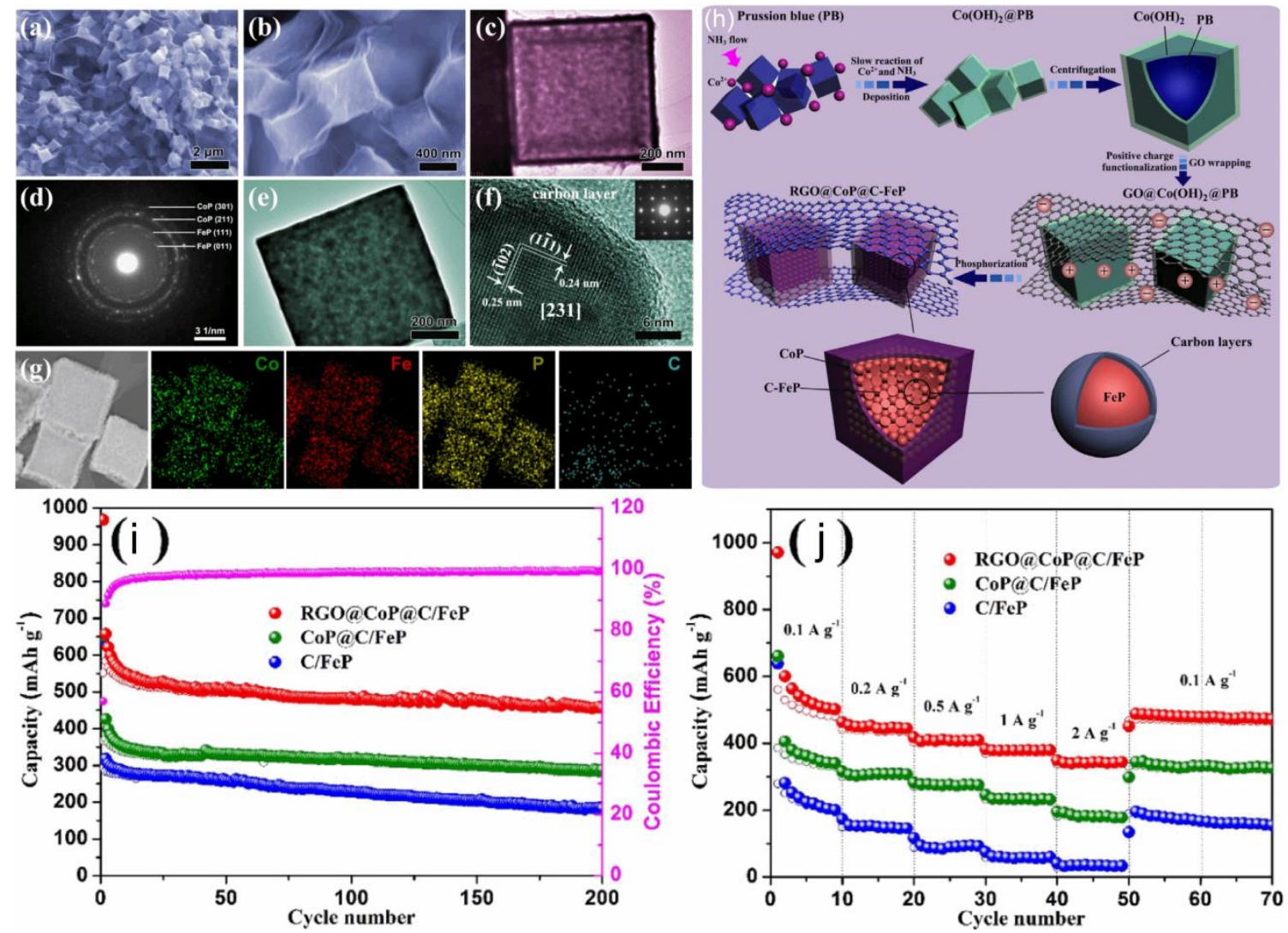

Fig. 11 (a-b) SEM images of the RGO@CoP@FeP composites; (c) Typical TEM image of core-shell structured CoP@FeP microcube; (d) Electron diffraction pattern corresponding to CoP@FeP microcube in (c); (e) TEM image of a FeP microcube; (f) TEM image of a porous C-FeP microcubes with inset corresponding electron diffraction pattern; (g) Elemental mapping images of Co, Fe, P, and C for the CoP@C-FeP microcubes; (h) Schematic illustration of the formation of the RGO interconnected core-shell structured RGO@CoP@C-FeP porous microcubes; (i) Cycling performance and (j) rate capability of the RGO@CoP@C-FeP, CoP@C-FeP, and C-FeP electrodes. Reproduced with permission ${ }^{157}$. Copyright (C) 2017 Elsevier Ltd. All rights reserved.

Some alloy based materials in group 15 have been designed in yolk-shell structured form, and outstanding electrochemical performances were achieved as well. Liu et al. fabricated hollow Sb@C yolk-shell spheres through a galvanic replacement method. TEM analysis showed that the Sb hollow yolk is covered by a highly-conductive thin shell. The internal void space between them could be regarded as a buffer zone for the full expansion of $\mathrm{Sb}$ nanoparticle units, thus preserving the structural integrity of the $\mathrm{Sb} @ \mathrm{C}$ and a stable SEI film. Therefore, these yolk-shell Sb@C particles displayed a reversible capacity of $\sim 280$ 
$\mathrm{mAh} \mathrm{g}^{-1}$ at $1000 \mathrm{~mA} \mathrm{~g}^{-1}$ after 200 cycles ${ }^{166}$. Another example is the yolk-shell $\mathrm{Sn}_{4} \mathrm{P}_{3} @ \mathrm{C}$ nanospheres reported by Liu et al. A top-down phosphorized approach was utilized with yolk-shell Sn@C precursor, causing the $\mathrm{Sn}_{4} \mathrm{P}_{3}$ nanoparticles to be completely protected by a thin, conformal, and self-supporting carbon shell. The as-prepared sample exhibited an extremely high capacity of $790 \mathrm{~mA} \mathrm{~h} \mathrm{~g}^{-1}$, superior rate capability (421 $\mathrm{mA} \mathrm{h} \mathrm{g}^{-1}$ at $3 \mathrm{C}$ ), and stable cycling capability with a capacity of $360 \mathrm{~mA} \mathrm{~h} \mathrm{~g}^{-1}$ after 400 cycles at $1.5 \mathrm{C}$. They concluded that this rationally designed void space in the yolk-shell structure allows for the expansion of $\mathrm{Sn}_{4} \mathrm{P}_{3}$ without deforming the carbon shell or disrupting the SEI on the outside surface $^{167}$.

\section{Conclusion and perspectives}

Research on SIBs has increased rapidly under the trend of searching for alternative substitutes for LIBs, much work has been done on anode materials of SIBs, and rational structural design is regarded as an effective way to improve their electrochemical performances. In this review, we have summarized different types of anode materials for SIBs according to their reaction mechanism. The main problems of each type have been pointed out, such as low specific capacity and poor rate capability for the insertion type materials, and huge volume expansion for the conversion and alloying reaction materials during charge/discharge processes. Specific structural designs have been illustrated for each type of anode material with unique structure and outstanding electrochemical properties. The structural design of anode materials for SIBs can be generally classified into three types: (1) nanostructures; (2) porous or hollow structures; and (3) core-shell or yolk-shell structures. Sometimes, these special structures are combined when fabricating anode materials for SIBs in order to achieve better electrochemical performance. Various anode materials with special structures in SIBs have been summarized in Table 1.

Table 1 Summary of some anode materials with special structures in sodium-ion batteries

\begin{tabular}{|c|c|c|c|c|c|}
\hline Type of material & BET surface area $\left[\mathrm{m}^{2} \mathrm{~g}^{-1}\right]$ & Initial C.E. [\%] & Cyclability $\left[\mathrm{mA} \mathrm{h} \mathrm{g}^{-1}\right]$ & Rate capability [mA h g $\left.{ }^{-1}\right]$ & Ref. \\
\hline Hollow carbon nanowires & / & 50.5 & 206.3 at $50 \mathrm{~mA} \mathrm{~g}^{-1}$ after 400 cycles & 150 at $0.5 \mathrm{~A} \mathrm{~g}^{-1}$ & 28 \\
\hline Hollow carbon nanospheres & 410 & 41.5 & $\sim 200$ at $100 \mathrm{~mA} \mathrm{~g}^{-1}$ after 100 cycles & 50 at $10 \mathrm{~A} \mathrm{~g}^{-1}$ & 41 \\
\hline Carbon nanosheet frameworks & 196.6 & 57.5 & 225 at $100 \mathrm{~mA} \mathrm{~g}^{-1}$ after 200 cycles & $\sim 50$ at $10 \mathrm{~A} \mathrm{~g}^{-1}$ & 35 \\
\hline N-doped carbon nanofibers & / & 41.8 & 134 at $200 \mathrm{~mA} \mathrm{~g}^{-1}$ after 200 cycles & 73 at $20 \mathrm{~A} \mathrm{~g}^{-1}$ & 34 \\
\hline $\mathrm{N}$-doped porous carbon fiber & 1508 & 46 & 222 at $50 \mathrm{~mA} \mathrm{~g}^{-1}$ after 100 cycles & 72 at $10 \mathrm{~A} \mathrm{~g}^{-1}$ & 33 \\
\hline $\mathrm{H}_{3} \mathrm{PO}_{4}$-activated porous carbon & 1272 & 27 & $\sim 190$ at $50 \mathrm{~mA} \mathrm{~g}^{-1}$ after 225 cycles & 71 at $5 \mathrm{~A} \mathrm{~g}^{-1}$ & 22 \\
\hline $\begin{array}{l}\text { Sandwich-like hierarchically porous } \\
\text { carbon/graphene }\end{array}$ & 825.9 & / & 250 at $1000 \mathrm{~mA} \mathrm{~g}^{-1}$ after 1000 cycles & / & 44 \\
\hline 3D Porous Carbon Frameworks & 467 & 34.7 & 99.8 at $5000 \mathrm{~mA} \mathrm{~g}^{-1}$ after 10000 cycles & 100 at $20 \mathrm{~A} \mathrm{~g}^{-1}$ & 38 \\
\hline Porous nitrogen doped carbon sphere & 95.1 & 40 & 200 at $200 \mathrm{~mA} \mathrm{~g}^{-1}$ after 600 cycles & 155 at $1 \mathrm{~A} \mathrm{~g}^{-1}$ & 42 \\
\hline Nitrogen-rich mesoporous carbon & 113 & 49.6 & 252 at $50 \mathrm{~mA} \mathrm{~g}^{-1}$ after 100 cycles & 49.8 at $2 \mathrm{~A} \mathrm{~g}^{-1}$ & 168 \\
\hline
\end{tabular}


3D N-doped graphene foams

3D hard carbon matrix

Graphene-based N-doped carbon sandwich nanosheets

Core-shell-structured hollow carbon nanofiber@nitrogen-doped porous carbon composite

Hierarchical porous carbons Hierarchical N/S-codoped carbon Reduced graphene oxide/carbon nanotubes sponge

$3 \mathrm{D}$ porous carbon-coated graphene composite

Nanocrystalline anatase $\mathrm{TiO}_{2}$

Carbon-coated $\mathrm{TiO}_{2}$ nanoparticles

Anatase $\mathrm{TiO}_{2}$ nanocubes

$\mathrm{TiO}_{2} / \mathrm{C}$ nanofiber

$\mathrm{TiO}_{2} /$ carbon hollow spheres

Yolk-Shell TiO ${ }_{2} @ \mathrm{C}$ nanocomposite

$\mathrm{Fe}_{2} \mathrm{O}_{3}$ nanocrystals anchored onto graphene nanosheets

3D Porous $\mathrm{Fe}_{2} \mathrm{O}_{3} @ \mathrm{C}$ nanocomposite

$\mathrm{Fe}_{2} \mathrm{O}_{3}$ multi-shelled core-shell microspheres

$\mathrm{SnO}_{2}$ decorated graphene nanocomposite

Yolk-shell $\mathrm{SnO}_{2} @ \mathrm{C}$ nanospheres

$\mathrm{SnO}_{2} @$ void@C porous nanowires

Hierarchical mesoporous $\mathrm{SnO}$ microspheres

$\mathrm{MoS}_{2} /$ electrospun carbon nanofiber $\mathrm{MoS}_{2}$ nanosheets

$\mathrm{MoS}_{2}$ nanoflowers

$3 \mathrm{D} \mathrm{MoS}_{2}$-graphene microspheres

Core shell $\mathrm{MoS}_{2} / \mathrm{C}$ nanospheres

Sn nanoparticles embedded in carbon

Ultrasmall Sn nanodots embedded inside N-doped carbon microcages Sn/Sb@porous carbon nanofiber Yolk-Shell Sn@C

Spherical nano-Sb@C composite $\mathrm{Sb}-\mathrm{C}$ nanofiber

$\mathrm{Sb} @ \mathrm{C}$ coaxial nanotubes

$\mathrm{Sb}$ nanorod array

Sb nanoparticles@3D carbon

Nanoporous $\mathrm{Al} / \mathrm{Sb}$ allloy

3D Ni/Sb hollow nanospheres

Hollow Sb@C yolk-shell spheres

P@carbon nanotube

P nanoparticles@graphene scrolls $\mathrm{P}$ in N-doped microporous carbon

Hollow P nanospheres
594 at $500 \mathrm{~mA} \mathrm{~g}^{-1}$ after 150 cycles 116 at $4000 \mathrm{~mA} \mathrm{~g}^{-1}$ after 3000 cycles

154 at $5000 \mathrm{~mA} \mathrm{~g}^{-1}$ after 10000 cycles

$\sim 140$ at $500 \mathrm{~mA} \mathrm{~g}^{-1}$ after 2500 cycles

$\sim 150$ at $500 \mathrm{~mA} \mathrm{~g}^{-1}$ after 200 cycles 150 at $500 \mathrm{~mA} \mathrm{~g}^{-1}$ after 3400 cycles

138 at $10000 \mathrm{~mA} \mathrm{~g}^{-1}$ after 10000 cycles

323 at $1000 \mathrm{~mA} \mathrm{~g}^{-1}$ after 1000 cycles

$\sim 140$ at $50 \mathrm{~mA} \mathrm{~g}^{-1}$ after 100 cycles

$\sim 125$ at $30 \mathrm{~mA} \mathrm{~g}^{-1}$ after 100 cycles

$\sim 100$ at $1680 \mathrm{~A} \mathrm{~g}^{-1}$ after 1000 cycles

$\sim 212$ at $200 \mathrm{~mA} \mathrm{~g}^{-1}$ after 1000 cycles

$\sim 140.4$ at $100 \mathrm{~mA} \mathrm{~g}^{-1}$ after 100 cycles

$\sim 150$ at $200 \mathrm{~mA} \mathrm{~g}^{-1}$ after 2000 cycles

$\sim 400$ at $100 \mathrm{~mA} \mathrm{~g}^{-1}$ after 200 cycles

$\sim 400$ at $2000 \mathrm{~mA} \mathrm{~g}^{-1}$ after 1400 cycles

$\sim 1200$ at $800 \mathrm{~mA} \mathrm{~g}^{-1}$ after 200 cycles

$\sim 300$ at $100 \mathrm{~mA} \mathrm{~g}^{-1}$ after 100 cycles

$\sim 928.9$ at $100 \mathrm{~mA} \mathrm{~g}^{-1}$ after 100 cycles

401 at $50 \mathrm{~mA} \mathrm{~g}^{-1}$ after 50 cycles

$\sim 300$ at $160 \mathrm{~mA} \mathrm{~g}^{-1}$ after 50 cycles

$\sim 200$ at $1000 \mathrm{~mA} \mathrm{~g}^{-1}$ after 500 cycles

$\sim 260$ at $10000 \mathrm{~mA} \mathrm{~g}^{-1}$ after 300 cycles

$\sim 260$ at $1000 \mathrm{~mA} \mathrm{~g}^{-1}$ after 1500 cycles

322 at $1500 \mathrm{~mA} \mathrm{~g}^{-1}$ after 600 cycles

337 at $1000 \mathrm{~mA} \mathrm{~g}^{-1}$ after 300 cycles

415 at $1000 \mathrm{~mA} \mathrm{~g}^{-1}$ after 500 cycles

332 at $500 \mathrm{~mA} \mathrm{~g}^{-1}$ after 300 cycles

$\sim 400$ at $500 \mathrm{~mA} \mathrm{~g}^{-1}$ after 200 cycles

$\sim 200$ at $1000 \mathrm{~mA} \mathrm{~g}^{-1}$ after 1000 cycles

350 at $100 \mathrm{~mA} \mathrm{~g}^{-1}$ after 500 cycles

$\sim 450$ at $200 \mathrm{~mA} \mathrm{~g}^{-1}$ after 400 cycles

240 at $1000 \mathrm{~mA} \mathrm{~g}^{-1}$ after 2000 cycles

620 at $200 \mathrm{~mA} \mathrm{~g}^{-1}$ after 100 cycles

$\sim 430$ at $100 \mathrm{~mA} \mathrm{~g}^{-1}$ after 500 cycles

$\sim 578.3$ at $100 \mathrm{~mA} \mathrm{~g}^{-1}$ after 200 cycles

$\sim 290$ at $6000 \mathrm{~mA} \mathrm{~g}^{-1}$ after 150 cycles

$\sim 280$ at $1000 \mathrm{~mA} \mathrm{~g}^{-1}$ after 200 cycles

1586.2 at $520 \mathrm{~mA} \mathrm{~g}^{-1}$ after 100 cycles

2172 at $250 \mathrm{~mA} \mathrm{~g}^{-1}$ after 150 cycles

450 at $1000 \mathrm{~mA} \mathrm{~g}^{-1}$ after 1000 cycles

$\sim 1000$ at $2600 \mathrm{~mA} \mathrm{~g}^{-1}$ after 600 cycles $\begin{array}{ll}51 \text { at } 2 \mathrm{~A} \mathrm{~g}^{-1} & 37 \\ \sim 150 \text { at } 5 \mathrm{~A} \mathrm{~g}^{-1} & 39 \\ 110 \text { at } 10 \mathrm{Ag}^{-1} & 27 \\ \sim 50 \text { at } 10 \mathrm{~A} \mathrm{~g}^{-1} & 46 \\ 47 \text { at } 10 \mathrm{~A} \mathrm{~g}^{-1} & 169 \\ 130 \text { at } 10 \mathrm{~A} \mathrm{~g}^{-1} & 43 \\ 200 \text { at } 10 \mathrm{~A} \mathrm{~g}^{-1} & 25 \\ 207 \text { at } 10 \mathrm{~A} \mathrm{~g}^{-1} & 170\end{array}$

$\sim 50$ at $2 \mathrm{~A} \mathrm{~g}^{-1} \quad 49$

$\sim 135$ at $0.8 \mathrm{~A} \mathrm{~g}^{-1}$

$\sim 108$ at $1.68 \mathrm{~A} \mathrm{~g} \mathrm{~g}^{-1}$

$\sim 164.9$ at $2 \mathrm{~A} \mathrm{~g}^{-1}$

$\sim 60.3$ at $2 \mathrm{~A} \mathrm{~g}^{-1}$

70 at $8 \mathrm{~A} \mathrm{~g}^{-1}$

$\sim 100$ at $2 \mathrm{~A} \mathrm{~g}^{-1} \quad 80$

$\sim 390$ at $8 \mathrm{~A} \mathrm{~g}^{-1}$

$\sim 800$ at $6 \mathrm{~A} \mathrm{~g}^{-1}$

207 at $0.8 \mathrm{~A} \mathrm{~g}^{-1}$

514 at $1 \mathrm{~A} \mathrm{~g}^{-1} \quad 64$

190 at $0.8 \mathrm{~A} \mathrm{~g}^{-1}$

$\sim 160$ at $3.2 \mathrm{~A} \mathrm{~g}^{-1}$

$\sim 304$ at $5 \mathrm{~A} \mathrm{~g}^{-1} \quad 114$

$\sim 200$ at $10 \mathrm{~A} \mathrm{~g}^{-1}$

$\sim 234$ at $10 \mathrm{~A} \mathrm{~g}^{-1}$

$\sim 200$ at $4 \mathrm{~A} \mathrm{~g}^{-1} \quad 110$

$\sim 349$ at $4 \mathrm{~A} \mathrm{~g}^{-1} \quad 122$

$\sim 200$ at $5 \mathrm{~A} \mathrm{~g}^{-1} \quad 130$

$\sim 400$ at $1 \mathrm{~A} \mathrm{~g}^{-1} \quad 124$

$\sim 200$ at $5 \mathrm{~A} \mathrm{~g}^{-1} \quad 136$

$\sim 270$ at $4 \mathrm{~A} \mathrm{~g}^{-1} \quad 147$

337 at $3 \mathrm{~A} \mathrm{~g}^{-1} \quad 149$

310 at $20 \mathrm{~A} \mathrm{~g}^{-1} \quad 148$

557.70 at $20 \mathrm{~A} \mathrm{~g}^{-1} \quad 145$

270 at $2 \mathrm{~A} \mathrm{~g} \mathrm{~g}^{-1} \quad 146$

$\sim 400$ at $3.3 \mathrm{~A} \mathrm{~g}^{-1} \quad 160$

230 at $6 \mathrm{~A} \mathrm{~g}^{-1} \quad 155$

$\sim 250$ at $5 \mathrm{~A} \mathrm{~g}^{-1} \quad 166$

$\sim 850$ at $5.2 \mathrm{~A} \mathrm{~g}^{-1} \quad 171$

$\sim 1000$ at $4 \mathrm{~A} \mathrm{~g}^{-1} \quad 153$

$\sim 300$ at $8 \mathrm{~A} \mathrm{~g}^{-1} \quad 142$

278.4 at $10.4 \mathrm{~A} \mathrm{~g}^{-1} \quad 163$ 
P@Ni-P core@shell

Core/shell CoP@C@3D RGO

Core-shell $\mathrm{CoP} / \mathrm{FeP}$ porous

microcubes

Yolk-shell $\mathrm{Sn}_{4} \mathrm{P}_{3} @$ C nanospheres

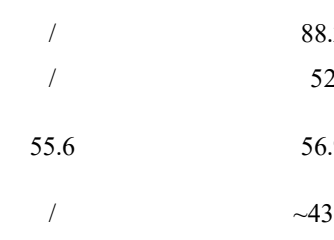

88.2

$\sim 400$ at $5000 \mathrm{~mA} \mathrm{~g}^{-1}$ after 2000 cycles

473 at $100 \mathrm{~mA} \mathrm{~g}^{-1}$ after 100 cycles

$\sim 500$ at $100 \mathrm{~mA} \mathrm{~g}^{-1}$ after 200 cycles

$\sim 360$ at $1500 \mathrm{~mA} \mathrm{~g}^{-1}$ after 400 cycles

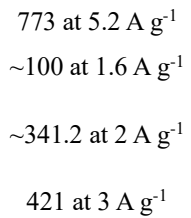

Nanostructures are the most common choice for structural design when considering the synthesis of high performance anode materials for SIBs, including nano particles, nanowires, nanosheets, etc, they could also make up 3D network structures. It can be found that, in all types of anode materials, the superior performance of nanostructured anode materials can be attributed to the small nanosized material, which can effectively reduce the Na-ion diffusion distance and provide high kinetics in the electrode. Porous or hollow structures are also popular among all the different kinds of anode materials for SIBs because these structures are inside the material and thus could increase the contact area with the electrolyte, providing a large number of active sites and also providing short sodium and electron diffusion paths that facilitate fast transport of sodium ion/electrons. Core-shell or yolk-shell structures are extremely valuable for fabricating conversion type and alloy based anode materials because these unique structures not only enable facile electrolyte infiltration to reduce the Na-ion diffusion length to improve the electrochemical reaction kinetics, but also prevent pulverization of the structure caused by Na-ion insertion/extraction. Especially in the yolkshell structure, the voids in materials can be considered as wonderful buffer zones to alleviate the structural strain during charge/discharge processes.

Although great progress has been achieved on anode materials of SIBs, there are still many challenges for their practical application. Most of the time, reports only focus on the advantages. The disadvantages of the nanomaterials are also worth to point out. Their low initial coulombic efficiency is still a serious problem. The reason is that the high-surface-area of nanosized materials that would cause large irreversible capacity loss associated with the electrolyte decomposition and the formation of SEI layer on the surface of the electrodes. In addition, the instability of nano particles could be a problem as well, it is highly challenging to retain the nanosize as they would easily aggregate together. For the porous and hollow structures, they would end up with high volumetric density because of the holes inside of the materials. The side reaction and the decomposition of electrolytes due to the high surface area are still the big obstacle for the real application. More importantly, the synthesis method for hollow structures are still very limited, which are normally based on solution process, the yield of product is comparatively low that could not meet the demand of scaling-up mass 
manufacture, how to control the pore/hollow size and shape are still problems that needs to be solved in the future ${ }^{172}$. For core-shell and yolk-shell structures, the volume expansion problem for high capacity anode materials cannot be fundamentally solved. Some reported anode materials with these kinds of complicated structures contain multistep synthetic process, but only displayed short cycling performance, which means the long-term cycling might finally destroy the hierarchical structures and deteriorate the electrochemical performance. How to fabricate the homogenous shell and control their thickness are still the challenge in real synthesis process. Therefore, in terms of structural design for anode materials, the ideal method for nanostructured materials would be making them to form secondary micro-sized particles, which could lower the contact area with electrolyte and become more stable in reaction. However, the nanostructured materials with micro-sized particle size are still far from ready for industrial manufacture. For porous, hollow, core-shell and yolk-shell structures materials, the aim is to simplify the complicated synthesis procedures and enhance their product yields. Besides, optimized electrolytes, additives, and binders should be explored to help further improve the electrochemical performance of anode materials for SIBs. Finding a balance between process costs and energy density is crucial for future practical application. This work is still expected to serve as a guide for future design of high performance anode materials for sodium-ion batteries.

\section{Acknowledgments}

The authors are grateful for financial support from the Automotive Australia 2020 Cooperative Research Centre (Auto CRC), the Baosteel-Australia Joint Research and Development Center (Baosteel Grant no. BA14006), the Australian Renewable Energy Agency (ARENA) Project (G00849), and the Innovative Group of Guangdong Province (Grant No. 2014ZT05N013). W. L. Wang is also supported by funding from the China Scholarship Council (No. 201606370024), and the authors thank Dr. Tania Silver for critical reading of the manuscript.

\section{Conflicts and interest}

There are no conflicts to declare.

\section{Notes and References}

1. B. Dunn, H. Kamath and J.-M. Tarascon, Science, 2011, 334, 928-935.

2. M. Armand and J.-M. Tarascon, Nature, 2008, 451, 652-657.

3. Y. Nishi, J. Power Sources, 2001, 100, 101-106. 
4. M. D. Slater, D. Kim, E. Lee and C. S. Johnson, Adv. Funct. Mater., 2013, 23, 947958.

5. W.-J. Li, C. Han, W. Wang, F. Gebert, S.-L. Chou, H.-K. Liu, X. Zhang and S.-X. Dou, Adv. Energy Mater., 2017, 1700274.

6. B. L. Ellis and L. F. Nazar, Curr. Opin. Solid St. M., 2012, 16, 168-177.

7. H. Kim, H. Kim, Z. Ding, M. H. Lee, K. Lim, G. Yoon and K. Kang, Adv. Energy Mater., 2016, 6, 1600943.

8. P. Adelhelm, P. Hartmann, C. L. Bender, M. Busche, C. Eufinger and J. Janek, Beilstein J. Nanotech., 2015, 6, 1016.

9. Q. Ni, Y. Bai, F. Wu and C. Wu, Adv. Sci., 2017, 4, 1600275.

10. C. Fang, Y. Huang, W. Zhang, J. Han, Z. Deng, Y. Cao and H. Yang, Adv. Energy Mater., 2016, 6, 1501727.

11. Z. Hu, S. Zhang, C. Zhang and G. Cui, Coordin. Chem. Rev., 2016, 326, 34-85.

12. Y. Kim, K. H. Ha, S. M. Oh and K. T. Lee, Chemistry, 2014, 20, 11980-11992.

13. J. Y. Hwang, S. T. Myung and Y. K. Sun, Chem. Soc. Rev., 2017, 46, 3529-3614.

14. P. Ge and M. Fouletier, Solid State Ionics, 1988, 28, 1172-1175.

15. Y. Wang, R. Chen, T. Chen, H. Lv, G. Zhu, L. Ma, C. Wang, Z. Jin and J. Liu, Energy Storage Materials, 2016, 4, 103-129.

16. H. Kang, Y. Liu, K. Cao, Y. Zhao, L. Jiao, Y. Wang and H. Yuan, J. Mater. Chem. A, 2015, 3, 17899-17913.

17. H. Hou, X. Qiu, W. Wei, Y. Zhang and X. Ji, Adv. Energy Mater., 2017, 7, 1602898.

18. M.-S. Balogun, Y. Luo, W. Qiu, P. Liu and Y. Tong, Carbon, 2016, 98, 162-178.

19. Z. Hu, Q. Liu, S. L. Chou and S. X. Dou, Adv. Mater., 2017, 29, 1700606.

20. Q. Xia, W. Li, Z. Miao, S. Chou and H. Liu, Nano Res., 2017, 10, 4055-4081.

21. D. Stevens and J. Dahn, J. Electrochem. Soc., 2000, 147, 1271-1273.

22. K.-L. Hong, L. Qie, R. Zeng, Z.-Q. Yi, W. Zhang, D. Wang, W. Yin, C. Wu, Q.-J. Fan, W.-X. Zhang and Y.-H. Huang, J. Mater. Chem. A, 2014, 2, 12733.

23. Y. Bai, Z. Wang, C. Wu, R. Xu, F. Wu, Y. Liu, H. Li, Y. Li, J. Lu and K. Amine, ACS Appl. Mater. Interfaces, 2015, 7, 5598-5604.

24. Y. Li, S. Xu, X. Wu, J. Yu, Y. Wang, Y.-S. Hu, H. Li, L. Chen and X. Huang, J. Mater. Chem. A, 2015, 3, 71-77.

25. D. Yan, X. Xu, T. Lu, B. Hu, D. H. C. Chua and L. Pan, J. Power Sources, 2016, 316, 132-138.

26. M. Li, R. Carter, A. P. Cohn and C. L. Pint, Carbon, 2016, 107, 109-115. 
27. D. Li, L. Zhang, H. Chen, J. Wang, L.-X. Ding, S. Wang, P. J. Ashman and H. Wang, J. Mater. Chem. A, 2016, 4, 8630-8635.

28. Y. Cao, L. Xiao, M. L. Sushko, W. Wang, B. Schwenzer, J. Xiao, Z. Nie, L. V. Saraf, Z. Yang and J. Liu, Nano Lett., 2012, 12, 3783-3787.

29. T. Chen, Y. Liu, L. Pan, T. Lu, Y. Yao, Z. Sun, D. H. C. Chua and Q. Chen, J. Mater. Chem. A, 2014, 2, 4117.

30. J. Jin, Z.-Q. Shi and C.-Y. Wang, Electrochim. Acta, 2014, 141, 302-310.

31. J. Jin, B.-J. Yu, Z.-Q. Shi, C.-Y. Wang and C.-B. Chong, J. Power Sources, 2014, 272, 800-807.

32. J. Zhu, C. Chen, Y. Lu, Y. Ge, H. Jiang, K. Fu and X. Zhang, Carbon, 2015, 94, 189195.

33. L. Fu, K. Tang, K. Song, P. A. van Aken, Y. Yu and J. Maier, Nanoscale, 2014, 6, 1384-1389.

34. Z. Wang, L. Qie, L. Yuan, W. Zhang, X. Hu and Y. Huang, Carbon, 2013, 55, 328334.

35. J. Ding, H. L. Wang, A. Kohandehghan, K. Cui, Z. W. Xu, B. Zahiri and X. H. Tan, ACS NANO, 2013, 7, 11004-11015.

36. S. Wang, L. Xia, L. Yu, L. Zhang, H. Wang and X. W. D. Lou, Adv. Energy Mater., 2016, 6, 1502217.

37. J. Xu, M. Wang, N. P. Wickramaratne, M. Jaroniec, S. Dou and L. Dai, Adv. Mater., 2015, 27, 2042-2048.

38. H. Hou, C. E. Banks, M. Jing, Y. Zhang and X. Ji, Adv. Mater., 2015, 27, 7861-7866.

39. Z. Yuan, L. Si and X. Zhu, J. Mater. Chem. A, 2015, 3, 23403-23411.

40. V. G. Pol, E. Lee, D. Zhou, F. Dogan, J. M. Calderon-Moreno and C. S. Johnson, Electrochim. Acta, 2014, 127, 61-67.

41. K. Tang, L. Fu, R. J. White, L. Yu, M.-M. Titirici, M. Antonietti and J. Maier, Adv. Energy Mater., 2012, 2, 873-877.

42. D. Li, H. Chen, G. Liu, M. Wei, L.-X. Ding, S. Wang and H. Wang, Carbon, 2015, 94, 888-894.

43. D. Xu, C. Chen, J. Xie, B. Zhang, L. Miao, J. Cai, Y. Huang and L. Zhang, Adv. Energy Mater., 2016, 6, 1501929.

44. Y. Yan, Y.-X. Yin, Y.-G. Guo and L.-J. Wan, Adv. Energy Mater., 2014, 4, 1301584.

45. H. Liu, M. Jia, B. Cao, R. Chen, X. Lv, R. Tang, F. Wu and B. Xu, J. Power Sources, 2016, 319, 195-201. 
46. Y. Qu, Y. Deng, Q. Li, Z. Zhang, F. Zeng, Y. Yang and K. Xu, Journal of Materials Science, 2016, 52, 2356-2365.

47. M. Li, L. Liu, P. Wang, J. Li, Q. Leng and G. Cao, Electrochim. Acta, 2017, 252, 523531.

48. Z. Yan, L. Liu, J. Tan, Q. Zhou, Z. Huang, D. Xia, H. Shu, X. Yang and X. Wang, J. Power Sources, 2014, 269, 37-45.

49. Y. Xu, E. M. Lotfabad, H. Wang, B. Farbod, Z. Xu, A. Kohandehghan and D. Mitlin, Chem. Commun., 2013, 49, 8973-8975.

50. G. Longoni, R. L. Pena Cabrera, S. Polizzi, M. D'Arienzo, C. M. Mari, Y. Cui and R. Ruffo, Nano Lett., 2017, 17, 992-1000.

51. Y. Yeo, J. W. Jung, K. Park and I. D. Kim, Sci Rep, 2015, 5, 13862.

52. Y. Xiong, J. Qian, Y. Cao, X. Ai and H. Yang, ACS Appl. Mater. Interfaces, 2016, 8, 16684-16689.

53. X. Yang, C. Wang, Y. Yang, Y. Zhang, X. Jia, J. Chen and X. Ji, J. Mater. Chem. A, $2015,3,8800-8807$.

54. F. Yang, Z. Zhang, Y. Han, K. Du, Y. Lai and J. Li, Electrochim. Acta, 2015, 178, 871-876.

55. S. Qiu, L. Xiao, X. Ai, H. Yang and Y. Cao, ACS Appl. Mater. Interfaces, 2017, 9, 345-353.

56. Y. Ge, H. Jiang, J. Zhu, Y. Lu, C. Chen, Y. Hu, Y. Qiu and X. Zhang, Electrochim. Acta, 2015, 157, 142-148.

57. G. Hasegawa, K. Kanamori, T. Kiyomura, H. Kurata, K. Nakanishi and T. Abe, Adv. Energy Mater., 2015, 5, 1400730.

58. C. Chen, H. Xu, T. Zhou, Z. Guo, L. Chen, M. Yan, L. Mai, P. Hu, S. Cheng, Y. Huang and J. Xie, Adv. Energy Mater., 2016, 6, 1600322.

59. M. J. R. Alcantara, P. Lavela, and J. L. Tirado, Chem. Mater., 2002, 14, 2847-2848.

60. C. N. He, S. Wu, N. Q. Zhao, C. S. Shi, E. Z. Liu and J. J. Li, ACS Nano, 2013, 7, 4459-4469.

61. G. Zhou, D.-W. Wang, F. Li, L. Zhang, N. Li, Z.-S. Wu, L. Wen, G. Q. Lu and H.-M. Cheng, Chemistry of Materials, 2010, 22, 5306-5313.

62. J.-W. Wen, D.-W. Zhang, Y. Zang, X. Sun, B. Cheng, C.-X. Ding, Y. Yu and C.-H. Chen, Electrochim. Acta, 2014, 132, 193-199.

63. F. Zhang, J. Zhu, D. Zhang, U. Schwingenschlogl and H. N. Alshareef, Nano Lett., 2017, 17, 1302-1311. 
64. X. Ao, J. Jiang, Y. Ruan, Z. Li, Y. Zhang, J. Sun and C. Wang, J. Power Sources, 2017, 359, 340-348.

65. Y. Zheng, T. Zhou, C. Zhang, J. Mao, H. Liu and Z. Guo, Angew. Chem. Int. Ed., 2016, 55, 3408-3413.

66. X. Zhang, G. Zhu, D. Yan, T. Lu and L. Pan, J. Alloy. Compd., 2017, 710, 575-580.

67. L. Wang, K. Zhang, Z. Hu, W. Duan, F. Cheng and J. Chen, Nano Res., 2013, 7, 199208.

68. X. Wang, K. Cao, Y. Wang and L. Jiao, Small, 2017, 13, 1700873.

69. Y. Guo, Y. Zhu, C. Yuan and C. Wang, Mater. Lett., 2017, 199, 101-104.

70. L. Wu, J. Lang, P. Zhang, X. Zhang, R. Guo and X. Yan, J. Mater. Chem. A, 2016, 4, 18392-18400.

71. J. Chen, Q. Ru, Y. Mo, S. Hu and X. Hou, Phys. Chem. Chem. Phys., 2016, 18, 18949-18957.

72. Y. Liu, B. H. Zhang, S. Y. Xiao, L. L. Liu, Z. B. Wen and Y. P. Wu, Electrochim. Acta, 2014, 116, 512-517.

73. S. Hariharan, K. Saravanan and P. Balaya, Electrochem. Commun., 2013, 31, 5-9.

74. Y. M. Sun, H. X. L., W. Luo and Y. H. Huang, ACS Nano, 2011, 5, 7100-7107.

75. Y. Wang, D. Su, C. Wang and G. Wang, Electrochem. Commun., 2013, 29, 8-11.

76. Z. Jian, P. Liu, F. Li, M. Chen and H. Zhou, J. Mater. Chem. A, 2014, 2, 13805.

77. M. Dirican, Y. Lu, Y. Ge, O. Yildiz and X. Zhang, ACS Appl. Mater. Interfaces, 2015, 7, 18387-18396.

78. Y. Liu, X. Fang, M. Ge, J. Rong, C. Shen, A. Zhang, H. A. Enaya and C. Zhou, Nano Energy, 2015, 16, 399-407.

79. X. Liu, T. Chen, H. Chu, L. Niu, Z. Sun, L. Pan and C. Q. Sun, Electrochim. Acta, 2015, 166, 12-16.

80. Z. Jian, B. Zhao, P. Liu, F. Li, M. Zheng, M. Chen, Y. Shi and H. Zhou, Chem. Commun., 2014, 50, 1215-1217.

81. S. Li, Y. Wang, J. Qiu, M. Ling, H. Wang, W. Martens and S. Zhang, RSC Adv., 2014, 4, 50148-50152.

82. M. B. Sreedhara, A. L. Santhosha, A. J. Bhattacharyya and C. N. R. Rao, J. Mater. Chem. A, 2016, 4, 9466-9471.

83. D. Su, X. Xie and G. Wang, Chemistry, 2014, 20, 3192-3197.

84. Y. Liu, Z. Cheng, H. Sun, H. Arandiyan, J. Li and M. Ahmad, J. Power Sources, 2015, 273, 878-884. 
85. N. Zhang, X. Han, Y. Liu, X. Hu, Q. Zhao and J. Chen, Adv. Energy Mater., 2015, 5, 1401123 .

86. Z.-G. Wu, Y.-J. Zhong, J. Liu, J.-H. Wu, X.-D. Guo, B.-H. Zhong and Z.-Y. Zhang, J. Mater. Chem. A, 2015, 3, 10092-10099.

87. H. Z. Li, L. Y. Yang, J. Liu, S. T. Li, L. B. Fang, Y. K. Lu, H. R. Yang, S. L. Liu and M. Lei, J. Power Sources, 2016, 324, 780-787.

88. F. Zheng, Q. Pan, C. Yang, X. Xiong, X. Ou, R. Hu, Y. Chen and M. Liu, Chemistry, 2017, 23, 5051-5058.

89. W. Ren, W. Zhou, H. Zhang and C. Cheng, ACS Appl. Mater. Interfaces, 2017, 9, 487-495.

90. L. Wan, W. Sun, J. Shen and X. Li, Electrochim. Acta, 2016, 211, 962-971.

91. Y. Liu, X. Wang, X. Song, Y. Dong, L. Yang, L. Wang, D. Jia, Z. Zhao and J. Qiu, Carbon, 2016, 109, 461-471.

92. J. Wang, C. Luo, T. Gao, A. Langrock, A. C. Mignerey and C. Wang, Small, 2015, 11, 473-481.

93. D. Su, S. Dou and G. Wang, Adv. Energy Mater., 2015, 5, 1401205.

94. W. Qin, T. Chen, L. Pan, L. Niu, B. Hu, D. Li, J. Li and Z. Sun, Electrochim. Acta, 2015, 153, 55-61.

95. S. H. Choi, Y. N. Ko, J.-K. Lee and Y. C. Kang, Adv. Funct. Mater., 2015, 25, 17801788.

96. C. Zhu, X. Mu, P. A. van Aken, Y. Yu and J. Maier, Angew. Chem. Int. Ed., 2014, 53, 2152-2156.

97. S. Zhang, X. Yu, H. Yu, Y. Chen, P. Gao, C. Li and C. Zhu, ACS Appl. Mater. Interfaces, 2014, 6, 21880-21885.

98. W. H. Ryu, J. W. Jung, K. Park, S. J. Kim and I. D. Kim, Nanoscale, 2014, 6, 1097510981.

99. Z. Hu, L. Wang, K. Zhang, J. Wang, F. Cheng, Z. Tao and J. Chen, Angewandte Chemie, 2014, 126, 13008-13012.

100. G. S. Bang, K. W. Nam, J. Y. Kim, J. Shin, J. W. Choi and S. Y. Choi, ACS Appl. Mater. Interfaces, 2014, 6, 7084-7089.

101. J. Li, D. Yan, X. Zhang, S. Hou, D. Li, T. Lu, Y. Yao and L. Pan, Electrochim. Acta, 2017, 228, 436-446.

102. X. Xiong, G. Wang, Y. Lin, Y. Wang, X. Ou, F. Zheng, C. Yang, J. H. Wang and M. Liu, ACS Nano, 2016, 10, 10953-10959. 
103. J.-H. Choi, C.-W. Ha, H.-Y. Choi, H.-C. Shin, C.-M. Park, Y.-N. Jo and S.-M. Lee, Electrochim. Acta, 2016, 210, 588-595.

104. J. Xie, L. Liu, J. Xia, Y. Zhang, M. Li, Y. Ouyang, S. Nie and X. Wang, Nano-Micro Letters, 2017, 10.

105. X. Zhang, J. Xiang, C. Mu, F. Wen, S. Yuan, J. Zhao, D. Xu, C. Su and Z. Liu, Electrochim. Acta, 2017, 227, 203-209.

106. J. Wang, C. Luo, J. Mao, Y. Zhu, X. Fan, T. Gao, A. C. Mignerey and C. Wang, ACS Appl. Mater. Interfaces, 2015, 7, 11476-11481.

107. X. Xie, D. Su, S. Chen, J. Zhang, S. Dou and G. Wang, Chem. Asian J., 2014, 9, 1611-1617.

108. D. Su, S. Dou and G. Wang, Chem. Commun., 2014, 50, 4192-4195.

109. Y. Liu, N. Zhang, H. Kang, M. Shang, L. Jiao and J. Chen, Chemistry, 2015, 21, 11878-11884.

110. B. Wang, Y. Xia, G. Wang, Y. Zhou and H. Wang, Chem. Eng. J., 2017, 309, 417425.

111. C. Chen, G. Li, Y. Lu, J. Zhu, M. Jiang, Y. Hu, L. Cao and X. Zhang, Electrochim. Acta, 2016, 222, 1751-1760.

112. X. Xie, Z. Ao, D. Su, J. Zhang and G. Wang, Adv. Funct. Mater., 2015, 25, 13931403.

113. Y. Liu, H. Kang, L. Jiao, C. Chen, K. Cao, Y. Wang and H. Yuan, Nanoscale, 2015, 7, $1325-1332$.

114. Y. Teng, H. Zhao, Z. Zhang, L. Zhao, Y. Zhang, Z. Li, Q. Xia, Z. Du and K. Świerczek, Carbon, 2017, 119, 91-100.

115. X. Xie, T. Makaryan, M. Zhao, K. L. Van Aken, Y. Gogotsi and G. Wang, Adv. Energy Mater., 2016, 6, 1502161.

116. J. S. Cho, J.-S. Park and Y. C. Kang, Nano Res., 2016, 10, 897-907.

117. C. Zhu, P. Kopold, W. Li, P. A. van Aken, J. Maier and Y. Yu, J. Mater. Chem. A, 2015, 3, 20487-20493.

118. S. Dong, C. Li, X. Ge, Z. Li, X. Miao and L. Yin, ACS Nano, 2017, 11, 6474-6482.

119. S. Yuan, Y. H. Zhu, W. Li, S. Wang, D. Xu, L. Li, Y. Zhang and X. B. Zhang, Adv. Mater., 2017, 29.

120. J. Mao, X. Fan, C. Luo and C. Wang, ACS Appl. Mater. Interfaces, 2016, 8, 71477155. 
121. C. Yue, Y. Yu, S. Sun, X. He, B. Chen, W. Lin, B. Xu, M. Zheng, S. Wu, J. Li, J. Kang and L. Lin, Adv. Funct. Mater., 2015, 25, 1386-1392.

122. Y. Liu, N. Zhang, L. Jiao, Z. Tao and J. Chen, Adv. Funct. Mater., 2015, 25, 214-220.

123. W. Chen and D. Deng, ACS Sustain. Chem. Eng., 2015, 3, 63-70.

124. C. Chen, K. Fu, Y. Lu, J. Zhu, L. Xue, Y. Hu and X. Zhang, RSC Adv., 2015, 5, 30793-30800.

125. B. Qu, C. Ma, G. Ji, C. Xu, J. Xu, Y. S. Meng, T. Wang and J. Y. Lee, Adv. Mater., 2014, 26, 3854-3859.

126. H. Zhu, Z. Jia, Y. Chen, N. Weadock, J. Wan, O. Vaaland, X. Han, T. Li and L. Hu, Nano Lett., 2013, 13, 3093-3100.

127. Y. H. Liu, Y. H. Xu, Y. J. Zhu, C. N. J., L. A. C., K. Xu and C. S. Wang, ACS Nano, 2013, 7, 3627-3634.

128. L. Baggetto, J. K. Keum, J. F. Browning and G. M. Veith, Electrochem. Commun., 2013, 34, 41-44.

129. K. H. Seng, M. H. Park, Z. P. Guo, H. K. Liu and J. Cho, Angew. Chem. Int. Ed., 2012, 51, 5657-5661.

130. H. Ying, S. Zhang, Z. Meng, Z. Sun and W.-Q. Han, J. Mater. Chem. A, 2017, 5, 8334-8342.

131. X. Xie, K. Kretschmer, J. Zhang, B. Sun, D. Su and G. Wang, Nano Energy, 2015, 13, 208-217.

132. Y. Xu, Y. Zhu, Y. Liu and C. Wang, Adv. Energy Mater., 2013, 3, 128-133.

133. L. Xiao, Y. Cao, J. Xiao, W. Wang, L. Kovarik, Z. Nie and J. Liu, Chem. Commun., 2012, 48, 3321-3323.

134. Y. M. Lin, P. R. Abel, A. Gupta, J. B. Goodenough, A. Heller and C. B. Mullins, ACS Appl. Mater. Interfaces, 2013, 5, 8273-8277.

135. Z. Zhang, X. Zhao and J. Li, Electrochim. Acta, 2015, 176, 1296-1301.

136. S. Li, Z. Wang, J. Liu, L. Yang, Y. Guo, L. Cheng, M. Lei and W. Wang, ACS Appl. Mater. Interfaces, 2016, 8, 19438-19445.

137. C. Zhang, X. Wang, Q. Liang, X. Liu, Q. Weng, J. Liu, Y. Yang, Z. Dai, K. Ding, Y. Bando, J. Tang and D. Golberg, Nano Lett., 2016, 16, 2054-2060.

138. J. Qian, X. Wu, Y. Cao, X. Ai and H. Yang, Angew. Chem. Int. Ed., 2013, 52, 46334636.

139. W. J. Li, S. L. Chou, J. Z. Wang, H. K. Liu and S. X. Dou, Nano Lett., 2013, 13, $5480-5484$. 
140. Y. Kim, Y. Park, A. Choi, N. S. Choi, J. Kim, J. Lee, J. H. Ryu, S. M. Oh and K. T. Lee, Adv. Mater., 2013, 25, 3045-3049.

141. J. Song, Z. Yu, M. L. Gordin, S. Hu, R. Yi, D. Tang, T. Walter, M. Regula, D. Choi, X. Li, A. Manivannan and D. Wang, Nano Lett., 2014, 14, 6329-6335.

142. W. Li, S. Hu, X. Luo, Z. Li, X. Sun, M. Li, F. Liu and Y. Yu, Adv. Mater., 2017, 29.

143. J. Duan, W. Zhang, C. Wu, Q. Fan, W. Zhang, X. Hu and Y. Huang, Nano Energy, 2015, 16, 479-487.

144. Y. N. Ko and Y. C. Kang, Chem. Commun., 2014, 50, 12322-12324.

145. L. Liang, Y. Xu, C. Wang, L. Wen, Y. Fang, Y. Mi, M. Zhou, H. Zhao and Y. Lei, Energy Environ. Sci., 2015, 8, 2954-2962.

146. W. Luo, P. Zhang, X. Wang, Q. Li, Y. Dong, J. Hua, L. Zhou and L. Mai, J. Power Sources, 2016, 304, 340-345.

147. N. Zhang, Y. Liu, Y. Lu, X. Han, F. Cheng and J. Chen, Nano Res., 2015, 8, 33843393.

148. Z. Liu, X.-Y. Yu, X. W. Lou and U. Paik, Energy Environ. Sci., 2016, 9, 2314-2318.

149. L. Wu, X. Hu, J. Qian, F. Pei, F. Wu, R. Mao, X. Ai, H. Yang and Y. Cao, Energy Environ. Sci., 2014, 7, 323-328.

150. Y. J. Zhu, X. G. Han, Y. H. Xu, Y. H. Liu, S. Y. Zheng, K. Xu, L. B. Hu and C. S. Wang, ACS Nano, 2013, 7, 6378-6386.

151. G. L. Xu, Z. Chen, G. M. Zhong, Y. Liu, Y. Yang, T. Ma, Y. Ren, X. Zuo, X. H. Wu, X. Zhang and K. Amine, Nano Lett., 2016, 16, 3955-3965.

152. J. Sun, G. Zheng, H. W. Lee, N. Liu, H. Wang, H. Yao, W. Yang and Y. Cui, Nano Lett., 2014, 14, 4573-4580.

153. L. Pei, Q. Zhao, C. Chen, J. Liang and J. Chen, ChemElectroChem, 2015, 2, 16521655 .

154. W. Li, Z. Yang, M. Li, Y. Jiang, X. Wei, X. Zhong, L. Gu and Y. Yu, Nano Lett., 2016, 16, 1546-1553.

155. J. Liu, Z. Yang, J. Wang, L. Gu, J. Maier and Y. Yu, Nano Energy, 2015, 16, 389-398.

156. W. Zhang, J. Mao, W. K. Pang, Z. Guo and Z. Chen, Electrochim. Acta, 2017, 235, 107-113.

157. Z. Li, L. Zhang, X. Ge, C. Li, S. Dong, C. Wang and L. Yin, Nano Energy, 2017, 32, 494-502.

158. W. J. Li, S. L. Chou, J. Z. Wang, H. K. Liu and S. X. Dou, Chem. Commun., 2015, 51, 3682-3685. 
159. W. Li, S. L. Chou, J. Z. Wang, J. H. Kim, H. K. Liu and S. X. Dou, Adv. Mater., 2014, 26, 4037-4042.

160. S. Liu, J. Feng, X. Bian, J. Liu and H. Xu, Energy Environ. Sci., 2016, 9, 1229-1236.

161. D.-H. Nam, K.-S. Hong, S.-J. Lim and H.-S. Kwon, J. Power Sources, 2014, 247, 423-427.

162. J. Sun, H.-W. Lee, M. Pasta, Y. Sun, W. Liu, Y. Li, H. R. Lee, N. Liu and Y. Cui, Energy Storage Materials, 2016, 4, 130-136.

163. J. Zhou, X. Liu, W. Cai, Y. Zhu, J. Liang, K. Zhang, Y. Lan, Z. Jiang, G. Wang and Y. Qian, Adv. Mater., 2017, 29, 1700214.

164. X. Ge, Z. Li and L. Yin, Nano Energy, 2017, 32, 117-124.

165. S. Liu, J. Feng, X. Bian, J. Liu, H. Xu and Y. An, Energy Environ. Sci., 2017, 10, 1222-1233.

166. J. Liu, L. Yu, C. Wu, Y. Wen, K. Yin, F. K. Chiang, R. Hu, J. Liu, L. Sun, L. Gu, J. Maier, Y. Yu and M. Zhu, Nano Lett., 2017, 17, 2034-2042.

167. J. Liu, P. Kopold, C. Wu, P. A. van Aken, J. Maier and Y. Yu, Energy Environ. Sci., $2015,8,3531-3538$.

168. H. Liu, M. Jia, N. Sun, B. Cao, R. Chen, Q. Zhu, F. Wu, N. Qiao and B. Xu, ACS Appl. Mater. Interfaces, 2015, 7, 27124-27130.

169. H. Wang, W. Yu, J. Shi, N. Mao, S. Chen and W. Liu, Electrochim. Acta, 2016, 188, 103-110.

170. D. Zhou, Y. Liu, W.-L. Song, X. Li, L.-Z. Fan and Y. Deng, Chem. Eng. J., 2017, 316, 645-654.

171. J. X. Song, Z. X. Yu, M. L. Gordin, H. S. Peng and D. H. Wang, ACS Nano, 2015, 9, 11933-11941.

172. X. W. Lou, L. A. Archer and Z. Yang, Adv. Mater., 2008, 20, 3987-4019. 